\title{
Article
}

\section{Hyperglycemia-induced cardiac contractile dysfunction in the diabetic heart}

Singh, Raphael M., Waqar, Tahreem, Howarth, Frank C., Adeghate, Ernest, Bidasee, Keshore and Singh, Jaipaul

Available at http://clok.uclan.ac.uk/20950/

Singh, Raphael M., Waqar, Tahreem, Howarth, Frank C., Adeghate, Ernest, Bidasee, Keshore and Singh, Jaipaul ORCID: 0000-0002-3200-3949 (2018) Hyperglycemia-induced cardiac contractile dysfunction in the diabetic heart. Heart Failure Reviews, 23 (1). pp. 37-54. ISSN 1382-4147

It is advisable to refer to the publisher's version if you intend to cite from the work. http://dx.doi.org/10.1007/s10741-017-9663-y

For more information about UCLan's research in this area go to http://www.uclan.ac.uk/researchgroups/ and search for <name of research Group>.

For information about Research generally at UCLan please go to http://www.uclan.ac.uk/research/

All outputs in CLoK are protected by Intellectual Property Rights law, including Copyright law. Copyright, IPR and Moral Rights for the works on this site are retained by the individual authors and/or other copyright owners. Terms and conditions for use of this material are defined in the policies page.

\section{CLoK}

Central Lancashire online Knowledge www.clok.uclan.ac.uk

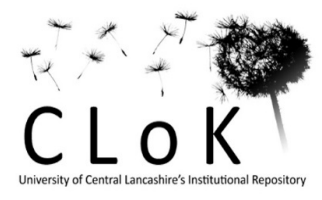




\title{
Title Page
}

\section{Hyperglycaemia-Induced Cardiac Contractile Dysfunction in the Diabetic Heart}

\author{
Raphael M. Singh ${ }^{1,2}$, Tahreem Waqarr ${ }^{1}$, Frank C. Howarth ${ }^{3}$, Ernest Adeghate ${ }^{4}$, Keshore \\ Bidasee $^{5}$ and Jaipaul Singh ${ }^{1}$
}

${ }^{1}$ School of Forensic and Applied Sciences, University of Central Lancashire, Preston, PR1 2HE, England, United Kingdom. ' Faculty of Medicine and Health Sciences, University of Guyana, Turkeyen, Georgetown, Guyana.

${ }^{3}$ Department of Physiology and ${ }^{4}$ Department of Human Anatomy, College of Medicine and Health Sciences, United Arab Emirates University, AL-AIN, United Arab Emirates. ${ }^{5}$ Department of Pharmacology and Experimental Neurosciences, University of Nebraska Medical Centre, Omaha, Nebraska, 68198, United States of America.

Corresponding Author: Raphael M. Singh, Faculty of Medicine and Health Sciences, University of Guyana, Turkeyen, Georgetown, Guyana. (Email: raphael_singh@yahoo.com Telephone: +5926285115)

Word Count: 8250 


\section{Abstract}

The development of a diabetic cardiomyopathy is a multifactorial process, and evidence is accumulating that defects in intracellular free calcium concentration $\left[\mathrm{Ca}^{2+}\right]_{i}$ or its homeostasis are related to impaired mechanical performance of the diabetic heart leading to a reduction in contractile dysfunction. Defects in ryanodine receptor, reduced activity of the sarcoplasmic reticulum calcium pump (SERCA) and, along with reduced activity of the sodium-calcium exchanger (NCX) and alterations in myofilament, collectively cause a calcium imbalance within the diabetic cardiomyocytes. This in turn is characterized by cytosolic calcium overloading or elevated diastolic calcium leading to heart failure. Numerous studies have been performed to identify the cellular, subcellular and molecular derangements in diabetes-induced cardiomyopathy (DCM), but the precise mechanism(s) is still unknown. This review focuses on the mechanism behind DCM, the onset of contractile dysfunction and the associated changes with special emphasis on hyperglycaemia, mitochondrial dysfunction in the diabetic heart. Further, management strategies, including treatment and emerging therapeutic modalities are discussed.

Key words: Contractile dysfunction, sarcoplasmic reticulum calcium ATPase (SERCA), hyperglycaemia, diabetic cardiomyopathy, calcium transients $\left[\mathrm{Ca}^{2+}\right]_{\mathrm{i}}$ 


\section{Diabetes mellitus (DM)}

Diabetes mellitus (DM) is a heterogeneous metabolic disorder characterised by chronic hyperglycaemia (HG) that results in dysfunction in the cell's ability to transport and utilize glucose [1]. Type 1 DM (T1DM), is caused by T lymphocyte-mediated autoimmune destruction of the pancreatic $\beta$-cells, resulting in insufficient insulin production and subsequent decrease in glucose utilization [2]. Type 2 DM (T2DM) results from an insulin resistance that instigates hypertrophy of the $\beta$-cell to compensate, and resulting in hyperinsulinemia leading to eventual insulin resistance $[3,4]$. Advanced failure of the $\beta$-cells in T2DM decreases the amount of insulin produced resulting in pathophysiological changes that produce elevated blood glucose levels (hyperglycaemia), impaired cellular glycolysis and pyruvate oxidation [5]. In chronic hyperglycaemia, comorbidities include some longterm complications as peripheral vascular disease, retinopathy, kidney failure, neuropathy and eventually, cardiac dysfunction/failure or cardiomyopathy [6].

Currently, more than 422 million people worldwide - almost one in every 11, suffer from DM and this number is likely to increase to 650 million within the next 15-20 years [7], making it one of the five leading causes of death in developed and developing countries. Between 1980 and 2014 the number of adults with diabetes quadrupled from 108 million to 422 million. The prevalence of DM was higher in the developed countries but now, the major increase in people with diabetes occurs in the developing countries such as China, India, and those in Middle East and Africa.

Type 2 DM (T2DM) is specifically epidemic due to the rising rates of obesity throughout the world. Over one billion people worldwide are overweight $(\mathrm{BMI}>25$ and $<29.9$ ) or obese $(\mathrm{BMI}>30)$ in most cases and they are also pre-diabetics [8]. With such high rates of morbidity and mortality, DM represents a major medical, sociological and economic challenge and burden to the national health services globally.

Cardiovascular diseases (CVDs) are the leading cause of death throughout the world and on the basis of 2011 death rate data, mortality owing to cardiovascular disease accounted a astounding 2150 people dying daily with an average of 1 death every 40 seconds [9]. Interesting, CVD- related mortality with DM have been reported to be about 65\% [10] and $68 \%$ of adults with DM older than 65 years die of some form of heart disease. The Framingham Heart Study demonstrated that the frequency of heart failure is five times greater in diabetic women and two times greater in diabetic men compared with age- 
matched control subjects $[11,12]$.

Diabetic heart disease is now recognized as an important and growing public health risk which affects the heart in three ways: cardiac autonomic neuropathy (CAN), coronary artery disease (CAD) due to accelerated atherosclerosis, and diabetic cardiomyopathy (DCM) [10]. DCM is a heart failure syndrome found in diabetic patients that is characterized by impaired myocardial relaxation dynamics or diastolic dysfunction, and structural abnormalities leading to left ventricular hypertrophy (LVH) or a combination of these [13]. Presently, DCM is defined as myocardial dysfunction (MD) in patients with DM in the absence of hypertension and structural heart diseases such as valvular heart disease or CAD [14].

Other features of DCM include: interstitial fibrosis, myocyte hypertrophy [15], lipid accumulation in cardiomyocytes and fetal gene reactivation [16]. Furthermore, DCM is also accompanied by comorbidities such as obesity, smoking, hypertension and others and these complications often precede the development of systolic dysfunction, CAD and heart failure [17].

With DM being a well-known risk factor for the development of heart failure, which leads to a poor quality of life in affected individuals, the situation now becomes complicated in treatment of DM resulting in alteration of the pharmacokinetics of anti-diabetic medications. Therefore, in this review we focus on the mechanism behind DCM, the onset of contractile dysfunction and the associated changes with special emphasis on hyperglycaemia, mitochondrial dysfunction in the diabetic heart and management strategies, including treatment and emerging therapeutic directions.

\section{Mechanism of DCM}

Several factors are involved in the development of diabetic cardiomyopathy, including metabolic, biochemical, and ultrastructural changes within the cardiac myocyte $[18,19]$. In particular, because of the primary role of mitochondria in ATP production, weakening of mitochondrial respiratory function is a key contributing factor to decreased contractile function of the diabetic heart. Numerous mechanisms have been proposed to contribute to this clinical situation, including oxidative stress, microvascular abnormalities, and decreased sarcoplasmic reticular calcium uptake [20]. Other proposed mechanisms include: subcellular component abnormalities, metabolic disturbances, cardiac autonomic dysfunction, alterations in the renin-angiotensin-aldosterone system (RAAS), and maladaptive immune 
responses [21]. However, the molecular mechanisms that cause this cardiac dysfunction are still largely undefined. An established hypothesis is that hyperglycemia plays a critical role in the development of DCM, though multiple complex mechanisms and the interplay of many metabolic and molecular events within the myocardium and plasma contribute to its pathogenesis. The principal metabolic abnormalities in DM are hyperglycemia and hyperlipidemia, all of which stimulate the production of reactive oxygen species (ROS) or the nitrogen species that cause most diabetic complications, including DCM and diabetic nephropathy [22]. These abnormalities further induce alterations in downstream transcription factors, which result in changes in gene expression, myocardial substrate utilization, myocyte growth, endothelial function and myocardial compliance.

The development of DCM is a multifactorial process, and accumulating evidence has revealed that defects in $\left[\mathrm{Ca}^{2+}\right]_{i}$ homeostasis are related to impaired mechanical performance of the diabetic heart leading to the prevalence of contractile dysfunction [23]. It has been suggested that diastolic dysfunction may be due to cardiomyocyte hypertrophy and myocardial fibrosis. In turn, at cellular level, these are associated with defects in calcium transport and mitochondrial calcium uptake due to mitochondrial dysfunction and reduced activity of SERCA pump which are all responsible for calcium sequestration during cardiomyocyte diastolic relaxation [24-26]. Also, there is much evidence that reduced activity of NCX, myocardial contractile protein collagen formation and fatty acid metabolism are also associated with diastolic dysfunction. In vivo functional changes include decreased ventricular filling, decreased ventricular ejection fraction, decreased fractional shortening, increased ventricular wall stiffness and increased pre-ejection time [17].

As stated in the aforementioned section, hyperglycaemia stimulates an increase in reactive oxygen species (ROS) and reactive carbonyl species (RCS) production, because of increased input of reducing equivalents into the mitochondrial electron transport chain [27-28]. Hyperglycaemia-induced cell damage is a consequence of increased flux through metabolic pathways (polyol pathway flux, advanced glycation- end product formation, activation of protein kinase C (PKC) isoforms and increased hexosamine pathway flux) [22,29]. Mitochondrial function is highly impaired by hyperglycaemic conditions in part because of decreased mitochondrial transcription factor A (TFAM) activity and/or expression [30-31]. These topics will be discussed more in-depth in subsequent sections. 


\section{Glucose metabolism regulation by insulin and fatty acids}

It was reported over 40 years ago [32] that glycolytic metabolism is increased in cardiac hypertrophy and congestive hearth failure and it is now well-known that cardiac glucose metabolism declines in diabetes [33] due to a decline in insulin, insulin resistance or increased availability of fatty acids. Healthy hearts derive most of their energy from free fatty acids and only a small proportion from circulating glucose while; in contrast, diabetic hearts use more fat and less glucose than normal hearts.

The diabetic heart is characterized by distinctive metabolic events including elevations in fatty acid uptake and oxidation combined with a decrease in glucose uptake and oxidation. A major factor in the elevated uptake and oxidation of fatty acids in cardiomyocytes has been linked to Increased release of fatty acids by the adipocyte and liver resulting in elevated circulating fatty acids and triglycerides. [34]. In the heart, utilization of glucose stimulated by insulin, is inhibited by fatty acid metabolism via transcriptional regulation of limiting enzymes. The generation of enzymes of fatty acid oxidation entails the transcriptional regulators PPAR $\alpha$ and/or PPAR $\beta$, which regulate gene expression of these enzymes and are elevated and activated in diabetic hearts [25]. It has been suggested that the presence of glucose reduces fatty acid metabolism, probably by increasing intracellular levels of malonyl CoA [36], while increased fat dependence also appears to play a role in the function of decreased glucose metabolism. The initial step in cardiomyocyte glucose usage is uptake, which is significantly regulated by insulin in the heart. In DM there is also a persistent reduction in cardiac glycolytic capacity [37] and glucose oxidation is further reduced by a decline in pyruvate dehydrogenase activity $[37,38]$.

The concept of limiting enzymes and limiting steps in glucose metabolism has been reported to contribute to development of DCM [27] where limiting steps have become potential sites of pathology. The concept of one such limiting step was explained by Randle et al. [32] in the 1960's and more recently by An and Rodrigues [5] relating to glucose uptake via the glucose transporters GLUT1 and GLUT4 in myocardial glucose metabolism. These authors underlined that enabling of glucose transport by insulin involves both the translocation of GLUT4 to the cell membrane and the upregulation of the transporter, an effect that is impaired in diabetes. It was reported that despite the significant reduction in glucose uptake, the size of the intracellular glucose pool is elevated in the type 1 diabetic heart. 
[31]. Data collected revealed that impaired GLUT4 activity in the diabetic heart does not limit glycolytic flux and would imply that key bottlenecks in glycolysis develop downstream from the glucose transporters in the diabetic heart.

Glycolysis is the metabolic pathway that involves a sequence of ten enzyme-catalysed reactions, which converts glucose into pyruvate. One such important limiting enzyme in the diabetic heart is phosphofructokinase (PFK), which catalyses the conversion of fructose-6phosphate to fructose 1,6 bisphosphate. Enhanced rates of fatty acid $\beta$-oxidation lead to elevations in cardiac levels of both acetyl CoA and citrate, and it has been shown previously that citrate is a potent inhibitor of PFK [40]. Thus, this enzyme is a key target of fatty acidmediated regulation of glycolysis. Owing to the fact that diabetes is associated with enhanced rates of fatty acid $\beta$ - oxidation and elevations in citrate levels, it has been proposed that PFK activity is diminished in the diabetic heart [40]. Further research also implicates this enzyme as a major sensor of the high-energy phosphate content of the heart [41]. Elevations in AMP kinase activity as well as low ATP/ADP ratio has shown to stimulate the activity of this allosteric enzyme.

Other researchers [42] have proposed data supporting a role for PFK in diabetes-mediated glycolytic impairment that correlate with elevations in glucose-6-phosphate levels and reductions in fructose 1,6 bisphosphate content. Based upon these findings, a bottleneck consequently develops in the glycolytic pathway of the diabetic heart, resulting in an increase in myocardial levels of glucose-6-phosphate and fructose-6- phosphate. These events have important pathological consequences, as they serve as substrates for four pathological pathways involved in the development of DCM (see Figure 1).

Other limiting steps/enzymes in regulation of glucose metabolism in the heart include: (I) the three- enzyme pyruvate dehydrogenase complex (PDH) and (II) Glyceraldehyde-3phosphate dehydrogenase (GAPDH) - especially during myocardial ischemia. 


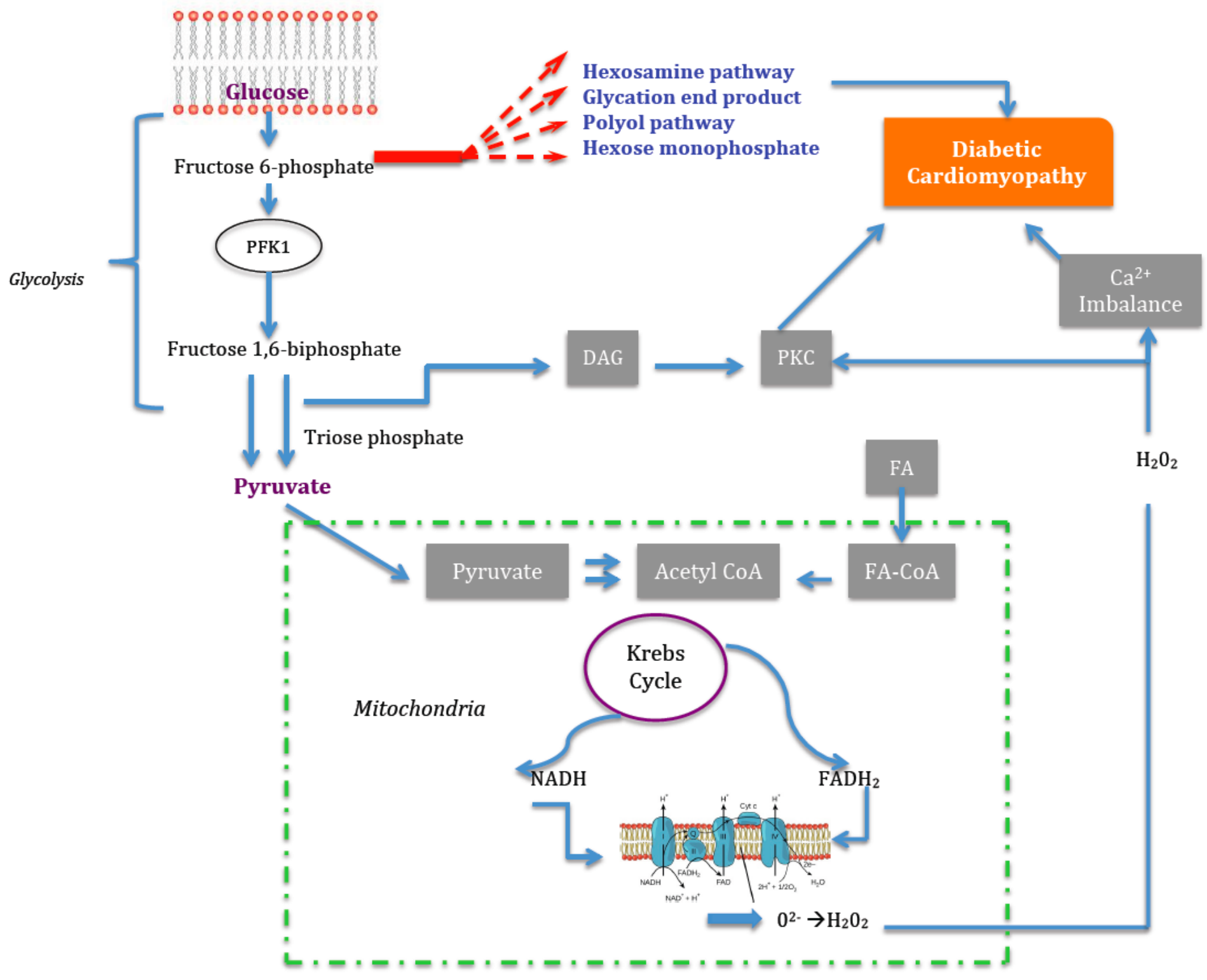

Figure 1: Flow diagram showing metabolic mechanisms of diabetic cardiomyopathy and how ROS from the mitochondria can leave the mitochondria as $\mathrm{H}_{2} \mathrm{O}_{2}$ and activate PKC in the cytosol. PFK- phosphofructokinase; DAG - diacylglycerol; PKC - protein kinase C; FA - fatty acid; NADH - nicotinamide adenine dinucleotide (reduced form); FADH - flavin adenine dinucleotide (reduced form); diagram drawn by hand.

\section{Mitochondrial dysfunction and changes in PKC activities in the diabetic heart}

Mitochondrial acetyl Co-A is a crucial factor of the citric acid cycle. In mammalian cells, mitochondrial acetyl-CoA is produced from pyruvate or by the $\beta$-oxidation of fatty acids, and 
then feeds into the citric acid cycle. Since the 1960's researchers [43] have highlighted the important role of acetyl-CoA in diabetic heart. Bowman [43] concluded that elevated levels of citric acid cycle intermediates in hearts of diabetic rats and in normal hearts perfused with fatty acids and ketone bodies are due largely to increased availability of acetyl-CoA.

Another factor that plays an important determinant role in the citric acid cycle flux is slowing of the respiratory chain flux. Several authors have suggested [44-47] that this event would contribute to the inhibition of $\alpha$-ketoglutarate dehydrogenase and elevate the $\mathrm{NADH} / \mathrm{NAD}^{+}$ratio, which in turn, would result in diminished citric acid flux.

Complexes in the respiratory chain are determined by the transcriptional activity of mitochondrial transcription factor A (TFAM), which is essential for mitochondrial DNA transcription and replication. It has been proposed [48] that TFAM transcriptional activity is decreased in diabetic cardiomyopathy and TFAM activity may be responsible for some of the alterations caused by hyperglycaemia. These researchers [48] investigated the effect of TFAM overexpression on hyperglycaemia-induced cytosolic calcium handling and mitochondrial abnormalities. They discovered that overexpression of TFAM dramatically affects the function of neonatal rat cardiomyocytes incubated in medium containing $30 \mathrm{mM}$ glucose. ATP content was reduced by $30 \%$ and mitochondrial calcium decreased by $40 \%$ after high glucose. Calcium transients were prolonged by $70 \%$ after high glucose, which was associated with diminished sarco(endo)plasmic reticulum $\mathrm{Ca}^{2+}$-ATPase $2 \mathrm{a}$ and cytochrome-c oxidase subunit 1 expression. In summary, it was demonstrated that: (I) hyperglycaemia increases the levels of O-GICNAcylated TFAM, which diminishes the activity of TFAM and reduces the activity of oxidative phosphorylation and (II) TFAM overexpression protected cell function against the damage induced by high glucose in cardiomyocytes.

An additional consequence of weakened respiratory chain flux is the generation of reactive oxygen species (ROS) - produced as electrons are diverted from the respiratory chain to the acceptor oxygen.

Figure 1 shows how $\mathrm{ROS}\left(\mathrm{O}^{2-}\right)$ generated from the mitochondria can leave the organelles as $\mathrm{H}_{2} \mathrm{O}_{2}$ and activate PKC in the cytosol. The outcome of PKC activation by ROS, in turn, triggers activation of NADPH oxidase and results in considerably increased cytosolic ROS content. Consequently, diabetes-mediated mitochondrial dysfunction contributes to the development of DCM by altering ATP generation and $\mathrm{Ca}^{2+}$ movement. 
Protein kinase $\mathrm{C}$ (PKC) has been shown to inhibit sarcoplasmic reticular $\mathrm{Ca}^{2+}$ pump and myofibrillar ATPase $[49,50]$ activities, and several investigators have suggested that subcellular changes in the diabetic heart may be due to alterations in the PKC activity and/or PKC-mediated signal transduction mechanism. Some examples include (I) increased phosphorylation of troponin-I in the diabetic heart has been considered to be due to the activation of PKC [51,52] and (II) diabetes is related with translocation of the $\varepsilon$-isoform of PKC from cytosolic to particulate fraction of cardiomyocytes. This change is prevented by the blockade of angiotensin II receptors, which are known to activate PKC [51] and it has also been established that concentration of diacylglycerol, a known activator of PKC [53] was increased in the diabetic heart.

One important study undertaken by Liu et al. [54] examined PKC activities in the homogenate, cytosolic, and particulate fractions from diabetic hearts. They found $\mathrm{Ca}^{2+}$ dependent PKC activity was increased by 43 and $51 \%$ in the homogenate fraction and $31 \%$ and $70 \%$ in the cytosolic fraction from the 4- and 8-weeks diabetic hearts while $\mathrm{Ca}^{2+}$ independent PKC activity was increased by $24 \%$ and $32 \%$ in the homogenate fraction and $52 \%$ and $89 \%$ in the cytosolic fraction respectively, both cases in comparison with control values. They also examined changes in the contents of different PKC isozymes in cardiac homogenate, cytosolic, and particulate fractions in diabetes induced by streptozotocin (STZ) in rats. The results showed relative protein contents of PKC- $\alpha-\beta-\varepsilon$ and $\zeta$, isozymes were increased by $43 \%, 31 \%, 48 \%$, and $38 \%$, respectively, in the homogenate fraction and by $126 \%, 119 \%, 148 \%$, and $129 \%$, respectively, in the cytosolic fraction of the 8 -weeks diabetic heart. These results provided reliable evidence that the increased myocardial PKC activity and increased protein contents of the cytosolic PKC isozymes are associated with subcellular alterations and cardiac dysfunction in the diabetic heart.

For more in-depth review and explanations on regulation of myocardial glucose, fatty acid metabolism diseases and dysfunctions, several excellent review articles have been published in the area of diabetes induced cardiac dysfunction [55-59].

\section{Role of HG and its biochemical pathways in the development of cardiac dysfunction}

Various mechanisms of HG are responsible for the generation of diabetes-induced heart disease, including metabolic abnormalities such as cellular calcium overload and altered 
calcium metabolism in cardiomyocytes leading to contractile dysfunction [60-63]. One major contributor to HG-induced diabetic abnormalities is increased oxidative stress along with depleted antioxidant defences and raised levels of reactive oxygen species (ROS). Persistent hyperglycaemia results in Increased glucose metabolism, which increases oxidative stress via the development of ROS from the mitochondria. ROS can cause damage to the mitochondria together with poly (ADP-ribose) polymerase-1 (PARP) activation leading to the inhibition of the cytosolic enzyme glyceraldehyde-3-phosphate dehydrogenase (GAPDH). This inhibition initiates a series of cellular processes, by activating pathways that lead to HGassociated cellular/tissue damage [64]. Inhibition of GAPDH diverts glucose from glycolytic pathways into alternative biochemical pathways, including advanced glycation end product (AGE) formation, hexosamine, polyol pathway, and protein kinase C (PKC) activation [65]. Increased formation of AGEs is involved in forming irreversible cross-links with macromolecules such as collagen leading to myocardial fibrosis, inactivation of SERCA2a and RyR2 calcium release channel, together with impaired cardiac contractility, relaxation and ventricular stiffness [66-69]. Increased polyol flux is associated with reduced levels of intracellular glutathione and an increase in cardiac cell apoptosis [70]. Furthermore, inhibition of this pathway has been claimed to provide protection for the heart from ischaemic injury [71]. The hexosamine biosynthetic pathway is known for reducing SERCA2a mRNA and protein expression, along with reduced SERCA2a promoter activity via increased nuclear O-GIcNAcylation. This results in prolonged calcium transients and impaired myocardial relaxation [72-73]. Finally, the activation of protein kinase C (PKC) via de novo synthesis of the lipid second messenger diacylglycerol (DAG) leads to vascular alterations at pathological, cellular and functional levels which include basement membrane thickening, extracellular matrix expansion, vascular permeability, enzymatic alterations such as $\mathrm{Na}^{+}-\mathrm{K}^{+}-$ ATPase, and MAP kinase, multifocal fibrosis, myocyte necrosis, decreased left ventricular performance and left ventricular hypertrophy [74]. Impaired calcium handling and cellular efflux may further contribute to impaired relaxation, or diastolic dysfunction. Overall, HG via multiple biochemical pathways results in myocardial, cellular and functional changes, all which contribute to the development of a cardiomyopathy leading to HF. Figure 2 illustrates these pathways as a flow chart. 


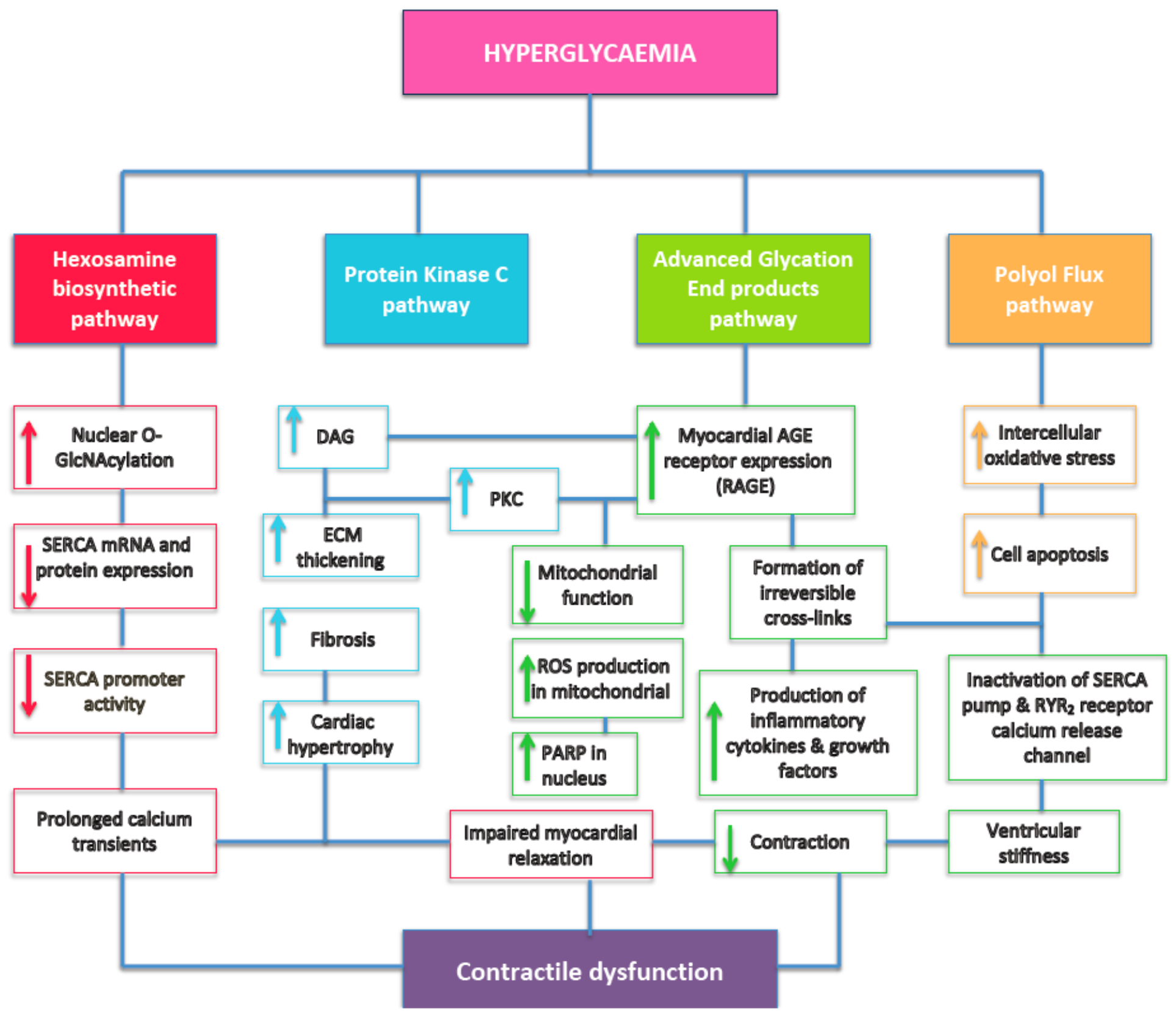

Figure 2: A schematic flow chart representation highlighting the role of hyperglycaemia and its biochemical pathways including hexosamine biosynthetic pathway, Protein Kinase C (PKC) pathway, advanced glycation end-products pathway and the Polyol flux pathway in the development of cardiac dysfunction. \{DAG; diacylglycerol, ECM; Extracellular Matrix, PARP; poly (ADP-ribose) polymerase-1, SERCA; sarcoplasmic reticulum $\mathrm{Ca}^{2+}-\mathrm{ATPase}$. See text for discussion; Diagram drawn by hand.

\section{Regulation of calcium in normal cardiac muscle}

The major function of the heart is to pump blood efficiently by virtue of an orchestrated contraction-relaxation cycle of the working cardiomyocytes. Contractility of these 
cardiomyocytes is regulated by a spatially defined programme of ion channels and exchangers that precisely control $\mathrm{Ca}^{2+}$ entry in and out of the cell and the SR. Regulation of contractility and hence, the control of $\mathrm{Ca}^{2+}$ release is principally achieved via the electrical activity of the sarcolemma. Depolarization of the cardiac cell membrane, during a normal action potential is sustained in the plateau phase by the activation of voltage-gated L-type $\mathrm{Ca}^{2+}$ channels (ICa,L) [75]. It is this small influx of $\mathrm{Ca}^{2+}$ via these channels that triggers a much larger release of $\mathrm{Ca}^{2+}$ from the $\mathrm{SR}$ by a process called calcium-induces calcium release (CICR). Upon activation of the SR, there is a transient rise in cytoplasmic $\mathrm{Ca}^{2+}$ concentration $\left[\mathrm{Ca}^{2+}\right]_{\mathrm{i}}$. This phenomena is commonly referred to as the calcium transient $\left[\mathrm{Ca}^{2+}\right]_{\mathrm{i}}$ and this CICR process is generally accepted as the major mechanism of $\mathrm{Ca}^{2+}$ release from the SR. $\mathrm{Ca}^{2+}$ release from the $S R$ is mediated by intracellular calcium receptors commonly known as ryanodine receptors (RyR), with type 2 RyRs being the most abundant intracellular $\mathrm{Ca}^{2+}$ channels in cardiomyocytes $[75,76]$. Contraction is initiated when free $\mathrm{Ca}^{2+}$ causes the interaction of the myofilaments via troponin $\mathrm{C}$ and the thick and thin filaments, namely actin and myosin leading to cell shortening. Exclusion of $\mathrm{Ca}^{2+}$ from the cytosol is achieved mainly by several mechanisms, including SR uptake via the SR $\mathrm{Ca}^{2+}$ transporter (SERCA), removal through the sarcolemma via the NCX and to a small extent by the $\mathrm{Ca}^{2+}$-ATPase pump [77-78]. These changes result in both cyclic increases and decreases in $\mathrm{Ca}^{2+}$ and in contractility of the individual myocytes.

In diabetic cardiomyopathy, it is well known that $\mathrm{Ca}^{2+}$ homeostasis is deranged leading to elevated diastolic $\mathrm{Ca}^{2+}$. This is due to a failure of SERCA to pump back $\mathrm{Ca}^{2+}$ into the SR, increased asyncrynous SR Ca ${ }^{2+}$ leak via RyRs and dysfunction of the NCX. These three $\mathrm{Ca}^{2+}$ transport proteins participate during calcium transient $\left[\mathrm{Ca}^{2+}\right] \mathrm{i}$ decline leading to a slow steady-state in resting $\mathrm{Ca}^{2+}$ [77]. In the new balanced state, a generously proportioned fraction of activating $\mathrm{Ca}^{2+}$ also enters the cell at each beat via the L-type $\mathrm{Ca}^{2+}$ channel (e.g. smaller $\mathrm{Ca}^{2+}$ release causes less $\mathrm{Ca}^{2+}$ inactivation). Consequently, these 4 major transporting proteins have been identified and they seem to contribute to the disturbed diastolic $\mathrm{Ca}^{2+}$ accumulation observed in the failing heart. Firstly, increased $\mathrm{Ca}^{2+}$ leak through RyR, secondly reduced SERCA activity, decreased trans-sarcolemal elimination of $\mathrm{Ca}^{2+}$ by the NCX and lastly the L-type $\mathrm{Ca}^{2+}$ channel [79-80]. These issues are further examined in the following text.

\section{Ryanodine receptor dysfunction}

A major feature in diabetic cardiomyopathy is the increased $\mathrm{Ca}^{2+}$ leak from the SR due to enhanced RyR open probability. Because leak, as measured by $\mathrm{Ca}^{2+}$ sparks, is increased with 
higher SR $\mathrm{Ca}^{2+}$ load, any intervention to increase SR $\mathrm{Ca}^{2+}$ load without reducing the leak decreases efficiency of ECC process with increased energy consumption with arrhythmias as potential side effects $[79,81]$.

RyRs were first observed in the 1970's as 'foot' structures in electron micrograph images of striated muscle filling the gaps that are found at specific junctions between the sarcolemma and the SR membrane [82-83]. Lai and colleagues identified the RyR as an integral SR membrane protein with a role in $\mathrm{Ca}^{2+}$ release [84]. The complementary DNA encoding three distinct RyR channels was cloned and the corresponding gene sequences obtained for three isoforms; RyR1 [85-86], RyR2 [87-88], and RyR3 [89]. It was not until the 1990s that the central role of RyRs through numerous biochemical, physiological, molecular and pharmacological studies and the physiological characteristics of excitation-contraction coupling (ECC) were recognized [89-91]. During the past decade numerous discoveries have been made of RyR2 gene mutations, which underlie the arrhythmogenesis leading to sudden cardiac death, which has added a new focus to the role of RyR2 dysfunction in cardiac disease [79-80, 92-93].

\section{Dysregulation of sarcoplasmic reticulum and $\mathrm{Na}^{+} / \mathrm{H}^{+}, \mathrm{Na}^{+} / \mathrm{K}^{+} \& \mathrm{Na}^{+} / \mathrm{Ca}^{2+}$ exchange}

The sarcoplasmic reticulum (SR) constitutes the main intracellular calcium store in striated muscle and it plays an important physiological role in the regulation of excitationcontraction-coupling (ECC) and of intracellular calcium concentrations during contraction and relaxation. Intracellular $\mathrm{pH}$ and $\left[\mathrm{Na}^{+}\right]$in the heart are regulated by the sarcolemmal membrane $\mathrm{Na}^{+} / \mathrm{H}^{+}$exchange pathway. DCM is characterized by reduced cardiac contractility due to direct changes in myocardium function independent of vascular disease. It is now becoming clear that cardiac dysfunction in chronic diabetes is I ntimately involved with $\mathrm{Ca}^{2+}$ handling abnormalities in the diabetic heart. These abnormalities occur mainly due to defects in sarcolemmal $\mathrm{Na}^{+} / \mathrm{K}^{+}$ATPase, $\mathrm{Na}^{+} / \mathrm{Ca}^{2+}$ exchange, $\mathrm{Na}^{+} / \mathrm{H}^{+}$exchange, $\mathrm{Ca}^{2+}$-channels and $\mathrm{Ca}^{2+}$-pump activities as well as changes in sarcoplasmic reticular $\mathrm{Ca}^{2+}$-uptake and $\mathrm{Ca}^{2+}$ release processes; these alterations may lead to the occurrence of intracellular $\mathrm{Ca}^{2+}$ overload.

This section investigates the alterations of cardiac sarcoplasmic reticulum $\mathrm{Ca}^{2+}$-ATPase activity and cardiac function. 
Early innovative work performed by Ganguly et al. [94] investigated the defective sarcoplasmic reticular calcium transport in diabetic cardiomyopathy. The results of this study provided some evidence that the depression in cardiac sarcoplasmic reticular calcium accumulation during diabetes is a consequence of insulin deficiency and associated chronic metabolic changes, but the hypothyroid condition that accompanies experimental diabetes does not appear to play any role in this defect. In follow-up research [95], experiments were designed to monitor rats that were injected with streptozotocin $(65 \mathrm{mg} / \mathrm{kg})$, killed 8-10 weeks later, and sarcolemmal membrane vesicles isolated from pooled ventricles. The results from these studies showed significant depressions in $\mathrm{Na}^{+} / \mathrm{K}^{+}$-adenosine triphosphatase (ATPase) activity and $\mathrm{Na}^{+} / \mathrm{Ca}^{2+}$ exchanges were observed in the diabetic preparations in comparison to control. Further, a striking depression in cardiac sarcolemmal $\mathrm{Na}^{+} / \mathrm{H}^{+}$exchange was observed in the diabetic animals in comparison to control.] Other studies, [96] focused on sarcolemmal $\mathrm{Ca}^{2+}$ transport in streptozotocin-induced diabetic cardiomyopathy in rats, provided results that indicated a depression in the ability of the cell to remove $\mathrm{Ca}^{2+}$ through $\mathrm{Na}^{+} / \mathrm{Ca}^{2+}$ exchange and $\mathrm{Ca}^{2+}$-pump mechanisms in sarcolemma. It was further concluded that these defects might contribute to the occurrence of intracellular $\mathrm{Ca}^{2+}$ overload and diabetic cardiomyopathy. Lun et al. [97] examined alterations in $\mathrm{Ca}^{2+}$ channels during the development of diabetic cardiomyopathy with specific binding of $3 \mathrm{H}$ nitrendipine studied at different concentrations. The outcome of their studies showed significant decrease in both dissociation constant and maximal number of $3 \mathrm{H}$-nitrendipine binding observed after 3 and 8 weeks. Also, it was revealed that treatment of diabetic animals with insulin prevented the occurrence of these changes in the myocardium. In summary, a relationship was seen between number of $3 \mathrm{H}$-nitrendipine binding sites and increased affinity of $\mathrm{Ca}^{2+}$ channels with the former partly explaining the depressed cardiac contractile force development in chronic diabetes, and latter, partly explaining the increased sensitivity of diabetic heart to $\mathrm{Ca}^{2+}$.

Further work by Dhalla et al. [98] highlighted the fact that while reductions in sarcoplasmic reticular $\mathrm{Ca}^{2+}$ pump and $\mathrm{Ca}^{2+}$ release channel function are associated with cardiac dysfunction, alterations in sarcolemmal $\mathrm{Na}^{+} / \mathrm{Ca}^{2+}$ exchanger and $\mathrm{Na}^{+} / \mathrm{K}^{+}$ATPase activities contribute to intracellular $\mathrm{Ca}^{2+}$ overload at late stages of diabetes. The constant buildup of $\mathrm{Ca}^{2+}$ in mitochondria produces $\mathrm{Ca}^{2+}$ overload in these organelles, and this change induces impairment of energy production, depletion of energy stores, as well as further promotion of oxidative stress in chronic diabetes. These observations, coupled with generation of 
oxyradicals results in the opening of mitochondrial pores, leakage of toxic proteins and myocardial cell damage in diabetes, supports the view that alterations in sarcoplasmic reticular and mitochondrial functions produce intracellular $\mathrm{Ca}^{2+}$ overload and therefore, play an critical role in the development of cardiac dysfunction in DCM.

Numerous researchers conducted other studies on the sarcoplasmic reticulum transport mechanism. Some of these are explained in the following text.

In cardiac muscle, the SR has been shown to be the most active subcellular organelle implicated with the sequestration of activator calcium. SERCA 2a ATPase, together with sarcolemma NCX are responsible for lowering $\left[\mathrm{Ca}^{2+}\right]_{\mathrm{i}}$, leading to the relaxation of muscle. Experiments have shown that calcium binding and/or uptake by cardiac SR is altered in a variety of physiological and pathological states [99-101].

Studies involving molecular cloning have identified a family of SERCA pumps encoded by the three homologous genes, SERCA1, SERCA2 and SERCA3 Of the 3 genes. The gene of interest here is the SERCA2, which is alternately spliced and encodes SERCA2a and SERCA2b isoforms [102]. SERCA2b isoform is expressed ubiquitously and is associated with inositol triphosphate (IP3) gated $\mathrm{Ca}^{2+}$ stores, whereas SERCA2a is the primary isoform expressed in the heart [103]. SERCA-2a ATPase is the major protein pump involved in the process of calcium reuptake into the sarcoplasmic reticulum [103]. Previous studies employing rats, mouse and rabbits have demonstrated that the expression of SERCA pump gradually increases during development [104-105]. Several other studies have shown that DCM is associated with decreased contractility and impaired relaxation [61]. As explained, the expression levels of SERCA pump protein appear to be a critical determinant of cardiac contractility. SERCA2a mRNA expression and protein level and activity have been demonstrated to be down-regulated in streptozotocin-induced (STZ) type 1 DM and the alteration of SERCA expression is accompanied by functional changes [105-106]. Studies from many laboratories have demonstrated that the expression level of SERCA is significantly decreased in pressure overload (Po) induced hypertrophy and HF [105-107]. Within these studies, the main finding has been decreased SR $\mathrm{Ca}^{2+}$ transport and function. In addition to animal studies on cardiac diseases, there is considerable evidence for alterations in $\mathrm{SR} \mathrm{Ca}^{2+}$ transport and function. In end stage human $\mathrm{HF}$, intracellular $\mathrm{Ca}^{2+}$ measurements using Fura-2 have shown markedly prolonged $\mathrm{Ca}^{2+}$ transients $\left[\mathrm{Ca}^{2+}\right] \mathrm{i}$ in both $\mathrm{Ca}^{2+}$ release and uptake phases in muscle samples from human hearts [102]. Further, other research by 
Connelly and colleagues, revealed substantial reduction of SERCA-2a ATPase in diabetic Ren2 rats [109]. Upon examining the abundance of the inhibitory protein PLB, which is a regulator of SERCA 2a ATPase, a reduction of the active, phosphorylated from of PLN was observed in the diabetic state that is similar to that seen in the human hearts. Thus, it was predicted to reduce calcium transport and prevent actomyosin dissociation contributing to delayed relaxation and reduced contractility [110]. Lacombe et al. [111] reported that diabetes-induced diastolic dysfunction together with preserved overall systolic performance is coupled with abnormalities of intra-myocyte calcium regulation. Their findings included, prolonged $\mathrm{Ca}^{2+}$ transient decay, reduced intra-SR $\mathrm{Ca}^{2+}$ stores, reduced $\mathrm{Ca}^{2+}$ sparks, and decreased SERCA2a protein content, which were all consistent with decreased SR $\mathrm{Ca}^{2+}$ reuptake during the relaxation phase of cardiac myocytes. The decrease in SR $\mathrm{Ca}^{2+}$ load, combined with decreased ECC efficiency may contribute to the decrease in $\mathrm{Ca}^{2+}$ transient amplitude and $\mathrm{Ca}^{2+}$ spark frequency. One alternative mechanism for this approach could be defined as a compensatory mechanism via reduced SR $\mathrm{Ca}^{2+}$ leak which will enhance SR $\mathrm{Ca}^{2+}$ load $[103,112]$ leading to the conclusion that impaired calcium reuptake during the diastolic phase, results from an impaired SERCA pump function.

Dhalla et al. [58] reported that activation of sympathetic nervous system and RAAS as well platelet aggregation, endothelial dysfunction and generation of oxidative stress promote differential changes in SR activities and protein content during the development of diabetes. This result in alterations in SR function and SR remodeling occur in the diabetic heart. On the basis of these observations, it is suggested that oxidative stress and subcellular remodeling due to hormonal imbalance and metabolic defects play a critical role in the genesis of heart failure during the development of DCM. Remodeling of other subcellular organelles, including sarcolemma and myofibrils, has also been reported during the development of DCM [113-114].

\section{Reduced calcium transients in diabetes mellitus}

During the last decade, accumulating evidence has been presented revealing that altered calcium homeostasis is of significant relevance for the pathophysiology of myocardial dysfunction and HF. Moreover, various mechanisms have been postulated as a result of many clinical and experimental studies. In addition, many outcomes have been identified from reduced $\mathrm{Ca}^{2+}$ transients and altered intracellular calcium cycling, reduced amplitude of $\mathrm{Ca}^{2+}$ transients with reduced systolic calcium concentrations and increased diastolic calcium 
levels in isolated myocytes, together with decreased rates of SR calcium uptake in the failing human heart in type 1 DM [115-119]. Abnormal $\left[\mathrm{Ca}^{2+}\right]_{i}$ homeostasis has also been implicated in DCM and may precede clinical manifestation. Studies in cardiomyocytes have shown that diabetes results in impaired $\left[\mathrm{Ca}^{2+}\right]_{\mathrm{i}}$ homeostasis due to altered SERCA and NCX activity [120]. Belke et al. [121] investigated contractile performance and $\mathrm{Ca}^{2+}$ transients in Langendorff-perfused hearts and isolated cardiac myocytes. They showed that in diabetic mouse hearts there was a decrease in rates of contraction, relaxation, and pressure development along with $\mathrm{Ca}^{2+}$ transients; significantly lower diastolic and systolic levels of calcium in myocytes from diabetic hearts. Furthermore, the decay rate of the $\mathrm{Ca}^{2+}$ transient was significantly reduced in diabetic myocytes, suggesting a diminished capacity for cytosolic calcium removal not associated with a change in NCX activity. Their study revealed that this decrease in contractile performance of the insulin-resistant (T2DM) diabetic model parallels the decrease in contractile performance observed in insulin-deficient (T1DM) diabetic models. However, recent study by Salem et al. [122] demonstrated no significant alterations in $\mathrm{Ca}^{2+}$ transients and L-type $\mathrm{Ca}^{2+}$ current in ventricular myocytes from 10-11 months old Goto Kakizaki (GK) sedentary compared to control sedentary rats or by exercise training (2-3 months of treadmill exercise). A study by Zhang et al. [123] found no evidence to support the idea that altered $\mathrm{Ca}^{2+}$ homeostasis underlies the contractile deficit of DCM. They postulated that the slower action potential and reduced SERCA2a expression could explain the slower $\mathrm{Ca}^{2+}$ transient kinetics in diabetic rats, but not the contractile deficit. Instead, they suggest that the observed LV remodelling may play a crucial role that is explained elsewhere [124-125].

In conclusion, the observed changes in contractility and in $\left[\mathrm{Ca}^{2+}\right]_{i}$ handling are most likely attributable to functional disturbances of SERCA2a, NCX and RyR2 in this transitional phase of diabetes.

\section{Heart failure with normal ejection fraction}

Ejection fraction is the volume of blood (usually presented as a percentage) pumped out of the ventricles during each heartbeat or cardiac cycle. It is now extensively acknowledged that the clinical features of HF can occur in patients with normal left ventricular ejection fraction (LVEF) [126-128] a complex broadly referred to as HF with normal left ventricular ejection fraction (HFnEF). The finding of a reduced LVEF in patients with typical signs and 
symptoms of HF provides objective proof that the patients suffer from cardiac abnormality and makes it obvious that the patient's clinical syndrome is indeed HF.

LV diastolic dysfunction is most commonly observed among patients with hypertension as well as the elderly [129]. While asymptomatic advanced LV diastolic dysfunction is also predictive of the future occurrence of HF [130], it is not clear why a number of patients with LV diastolic dysfunction have HFnEF while others remain asymptomatic. LV diastolic dysfunction has been suggested as the initial manifestation of diabetic heart disease in both T1DM and T2DM patients. In the Strong Heart Study [131], which investigated the effect of DM on LV filling pattern in normotensive and hypertensive individuals, T2DM was associated with an impaired relaxation pattern independently of age, blood pressure (BP), LV mass and LV systolic function.

The occurrence of DM in HF is approximately 20-35\% [132] and is to some extent higher in patients with HFnEF, at 30-40\% [133]. HFnEF and T2DM commonly coexist. Both conditions are associated with hypertension, obesity and ageing [23], all of which promote the prevalence of HF. However, irrespective of underlying CVD, DM has a central role in HFnEF as demonstrated in the CHARM study [134] whereby the relative risk of cardiovascular death or HF hospitalization conferred by DM was significantly greater in patients with HFnEF compared with those with HFrEF [134]. The prevalence of HFnEF may be high even in asymptomatic and well-controlled diabetic subjects $[135,136]$. Regardless of the increased prevalence and poor outcome, pathophysiological features underlying HFnEF in DM remain uncertain [137]. A recent study by Ehl et al. [138] demonstrated a significantly lower LVEF in diabetic compared with non-diabetic patients $(\mathrm{P}<0.001)$ in a large patient population. Even though the difference was small, this finding may have important epidemiological impact, since LVEF is one of the most important predictors of survival. This hypothesis is supported by data from the Mayo clinic, which have confirmed a significantly worse survival of even asymptomatic diabetic patients with an LVEF of 50\% [139].

Various morphological changes occur in the diabetic heart leading to the abnormal physiological findings described above. These include increased extracellular collagen deposition, interstitial fibrosis, myocyte hypertrophy and intra-myocardial microangiopathy. These changes are probably secondary to altered myocardial glucose and free fatty acid metabolism (FFA) in DM as outlined in Figure 3. 


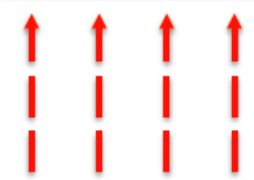

Hyperglycemia Hyperinsulinemia Dylipidemia AGEs
Heart Failure with Normal Ejection Failure

Myocardial Fibrosis

Myocyte Hypertrophy

Microangiopathy

Endothelial Dysfunction

Figure 3: A schematic representation of the pathophysiological mechanisms underlying HFnEF in diabetes mellitus; drawn by hand.

With respect to fibrosis and HFnEF, a population studied by van Heerebeek et al [140] showed different clinical characteristics to those observed in epidemiological studies. Consequently, as suggested by Connelly et al. [109], it should not be concluded that fibrosis does not contribute to HFnEF in DM. Several animal studies have demonstrated that fibrosis contributes to this syndrome [140] while human studies have shown that collagen volume fraction is increased approximately 2-fold in both DM and non-DM subjects with HFnEF [141]. Both fibrosis and cardiomyocyte are linked attributes to HFnEF in DM though the relative contribution of each remains under debate. Further research to unravel the pathophysiology of HFnEF in very well characterized patients and appropriate control subjects with a focus on the exercise response and the neuro-humoral axis is needed to establish therapeutic strategies [142].

\section{Role of myofilaments in cardiac dysfunction}

Myofilament properties have a major role in the governing cardiac relaxation. Though it is acknowledged that it is essential for the intracellular calcium concentration to decline in order to initiate and facilitate relaxation, the rate at which healthy myocardium relaxes is predominantly regulated by the properties of the myofilaments [143]. The peak of the $\left[\mathrm{Ca}^{2+}\right]_{\mathrm{i}}$ amplitude is usually reached long before the peak of force development, and once force development initiates to decline, the $\mathrm{Ca}^{2+}$ concentration is near or below the concentration where the myofilament can begin activation. 
DM is also known to be associated with a loss of cardiac myofibrils [144], which are the main contractile components for muscle contraction. Severe loss of myofibrils can lead to decreased contraction and cardiac output that are frequently reported in diabetic patients. Experiments conducted by Pierce and Dhalla [145], demonstrated that the basal ATPase activity of myofibrils from diabetic hearts was significantly lower than the controls over 8 weeks. Their results also highlighted: (i) the basal and $\mathrm{Ca}^{2+}$ stimulated ATPase activities in diabetic rats demonstrated a greater sensitivity to $\mathrm{KCl}$ than control preparations, (ii) the myofibrillar basal ATPase, unlike $\mathrm{Ca}^{2+}$ stimulated ATPase, in diabetic animals exhibited a greater sensitivity to ethylene glycol and (iii) supports the view regarding the presence of some subtle structural and conformational changes in diabetic myofibrils. In subsequent work [146], diabetes was introduced in rats where they were maintained in a diabetic state for 6 weeks and then given 2 weeks of insulin treatment in vivo. The results obtained emphasized: (i) $\mathrm{Mg}^{2+}$-ATPase and $\mathrm{Ca}^{2+}$-stimulated ATPase activities were depressed in diabetic rat hearts in comparison to control, (ii) the depression in myofibrillar ATPases was of gradual onset as no changes were detected 2 weeks after inducing diabetes, (iii) $\mathrm{Mg}^{2+}$ ATPase activity of myofibrillar preparations from control and diabetic hearts responded differently to N-ethylmaleimide modification, and interestingly and (iv) myofibrillar sulfhydryl reactivity to 5,5'-dithiobis (2-nitrobenzoic acid) was significantly depressed in diabetic preparations in comparison to control and insulin-treated diabetic animals.

While many studies focused on animal studies, Jweied and colleagues [147] conducted a study to determine whether human diabetes mellitus is associated with depressed cardiac myofilament function. Assessment of Myofilament function was achieved by determination of the developed force-Ca ${ }^{2+}$ concentration relation in skinned cardiac cells from flash frozen human biopsies. Separate control experiments revealed that flash freezing of biopsy specimens did not affect myofilament function. In this study, all patients in the DM group were classified as T2DM patients, and most showed signs of diastolic dysfunction. Data from the results revealed that DM was associated with depressed myofilament function, that is, decreased $\mathrm{Ca}^{2+}$ sensitivity $(29 \%, \mathrm{P}<0.05$ vs. control) and a trend toward reduction of maximum $\mathrm{Ca}^{2+}$-saturated force $(29 \%, \mathrm{P}=0.08 \mathrm{vs}$. control). Results from this study highlighted that human diabetes mellitus is associated with decreased cardiac myofilament function and further, depressed cardiac myofilament $\mathrm{Ca}^{2+}$ responsiveness may underlie the decreased ventricular function characteristic of human diabetic cardiomyopathy. 


\section{Prevention, treatment and potential targets for DCM}

In order for proper and improved management options to be effective, it is essential to have better understanding of pathophysiology and pathogenesis in patients with DCM. These options include; lifestyle modification, glycaemic control, management of coexistent hypertension and heart failure. Some of aforementioned management options, in addition to emerging treatment modalities are discussed in the following section.

\section{Lifestyle modification}

Exercise training is necessary to maintain a healthy body and it is recognized that regular exercise with better diabetic control would have beneficial effects on the disease outcome. In a recent study [148] physical activity was associated with a significant reduction in cardiovascular disease and all-cause mortality in patients with DM in many clinical studies. Exercise training was beneficial for reducing the incidence of DCM in both human patients and animal models $[149,150]$. Weight loss, control of fat and regular physical activity can positively adjust metabolic abnormalities and thus improve systemic insulin resistance. Insulin resistance can be achieved by increasing post-receptor-signaling and increasing insulin-mediated glucose transport, which seems to be associated with signal transduction at the level of phosphatidylinositol 3-kinase and insulin receptor substrate $[151,152]$. In addition to exercise, maintaining healthy eating patterns that are suitable for diabetic patients can also be expected to show similar beneficial effects.

\section{Glycaemic control}

Clinical trials have demonstrated that poor glycaemic control has been associated with an increased risk of cardiovascular mortality - with an increase of $11 \%$ for every $1 \%$ rise in glycated haemoglobin $\left(\mathrm{HbA}_{1 \mathrm{c}}\right)$ level [153]. It is expected that the effects of tight glycaemic control would be beneficial to patients because microvascular disease plays an important pathogenic role in the development of DCM. In one case-controlled study using cardiac MRI in patients with T1DM it was demonstrated that rigorous glycemic control was associated with better DCM outcome parameters [154] while in animal studies, improved glycaemic control delayed DCM in animal models [155]. However, other studies (UK Prospective Diabetes Study) failed to show a significant benefit of intensive blood glucose control using either sulphonylureas or insulin on the risk of developing macrovascular disease in patients with Type II diabetes [156]. 


\section{Anti-diabetic medication}

There are various classes of anti-diabetic drugs, and their selection depends on the nature of the diabetes, age, as well as other factors. Some of the more popular and effective drugs will be discussed in this section. These include: metformin, thiazolidinediones, empagliflozin, GLP-1 and DPP-4.

Metformin, believed to be the most widely used medication for diabetes that is taken by mouth, upregulates cardiac autophagy, which is linked to DCM prevention and is primarily used to treat T2DM. Metformin facilitates glucose uptake and GLUT4 translocation in insulin-resistant cardiomyocytes and the myocardium by activating 5'-adenosine monophosphate-activated protein kinase [157]. This drug was reported to reduce mortality and improve the clinical outcome in overweight patients with HF and DM, however, metformin increase the production of lactate in the large intestine, which could potentially contribute to lactic acidosis [158].

Thiazolidinediones (TZDs) are a class of insulin sensitizers compounds for treating patients with T2DM. They act by increasing insulin sensitivity in skeletal muscle and adipose tissue through binding and activation of PPAR- $\psi$, a nuclear receptor that has a regulatory role in differentiation of cells [159].

Apart from insulin-sensitizing fat and skeletal muscle, TZDs increase the expression and function of glucose transporters in the heart, leading to improved glucose metabolism, and reduce non-esterified fatty acids (NEFA) utilization by the myocardium [160]. However, thiazolidinedione therapy can cause chronic symptoms that resemble heart failure. Therefore, the drug is generally not recommended in patients with heart failure.

Empagliflozin is a new anti-diabetic drug of the gliflozin class that was approved for treatment of T2DM in 2014. It is an inhibitor of sodium-glucose co-transporter 2 (SGLT-2), which reduces $\mathrm{HbA}_{1 \mathrm{c}}$ levels in patients with T2DM by controlling visceral adiposity, blood pressure, arterial stiffness, albuminuria, weight, oxidative stress, hyperinsulinemia, and circulating uric acid levels [161].

Glucagon-like peptide-1 (GLP-1) is a known incretin that has the ability to decrease blood sugar levels in a glucose-dependent manner by enhancing the secretion of insulin. Synthetic 
GLP-1, which has a longer half-life than natural GLP-1, has shown to attenuate myocardial apoptosis and enhance vasodilation [162]. This new group of drugs has shown promise in the management strategy in obese T2DM patients with DCM and further, GLP-1-based treatment has been associated with weight loss and lower hypoglycemia risks.

Dipeptidyl peptidase 4 (DPP-4) is an enzyme that metabolizes endogenous GLP-1. DPP-4 inhibitors can prevent cardiac diastolic dysfunction and cardiac hypertrophy by inhibiting fibrosis and oxidative stress in mouse models of insulin resistance and obesity [163].

\section{Statins}

Statins (hydroxymethylglutaryl CoA reductase inhibitors) is a class of drug that lowers the level of cholesterol in the blood by reducing the production of cholesterol by the liver. Statins works by inhibiting HMG-CoA reductase (3-hydroxy-3-methyl-glutaryl-coenzyme A reductase), an enzyme found in liver tissue that plays a key role in the production of cholesterol in the body.

In multiple clinical trials [164] it was found that the use of statins reduces cardiovascular mortality and events in patients with diabetes and vascular risk factors, and it is beneficial even for primary prevention in patients without established cardiovascular disease [165].

It has been reported that atorvastatin, a lipid-lowering agent, reduces myocardial fibrosis, intramyocardial inflammation, and improves LV function in rat models of experimental DCM, independently of its LDL-C-lowering capacity [166]. Likewise, fluvastatin is useful for attenuating cardiac dysfunction and myocardial interstitial fibrosis in rat models of the disease [167].

\section{Vasoactive medications - blockers and inhibitors}

Many vasoactive medications have been tried in both animal and human patients models with DCM, with variable results.

$\beta$-blocker is a class of medications that are particularly used to manage abnormal heart rhythms, and to protect the heart from myocardial infraction after a first heart attack.

Initially, there was a reluctance to use $\beta$-blockers in patients with diabetes for fear of adverse effects on insulin resistance and an unawareness of hypoglycaemia. However, with the recent advances in the understanding of $\mathrm{HF}$ and the realization of the importance of the SNS in the release of vasoactive substances, they have become an essential treatment for HF [168]. 
Earlier studies of $\beta$-blockers in the early 90's involved recruited patients with advanced HF and, although LV function improved, mortality did not $[169,170]$. However, subsequent studies enrolled patients with mild-to-moderate HF and showed significant reductions in mortality rate of $32 \%$ and $34 \%$ respectively [171,172]. The third generation $\beta$-blocker carvedilol, which antagonizes both $\alpha$ and $\beta$ receptors, has been proven to have a highly significant effect on mortality (67\% reduction) in patients with severe HF [173]. Other $\beta$ blocker such as bisoprolol and metoprolol have been shown in large-scale randomized controlled trials to reduce heart failure mortality [174] and more recently, Sharma et al. demonstrate that $\beta$-Adrenoreceptor blockers were effective in experimental models of DCM [175].

The importance of (RAAS) antagonism in the prevention of diabetic CVD has demonstrated the key role that the RAAS plays in diabetic CVD onset and development. Angiotensin converting enzyme (ACEi) inhibitors and angiotensin II receptor blockers (ARB) represent the first line therapy for primary and secondary CVD prevention in patients with diabetes [176]. $(A C E i)$, renin inhibitor (aliskiren) and (ARB) were all shown to be protective against DCM in rat models [177]. Other studies have demonstrated that ACEis and ARBs were also beneficial in both human and animal models of DCM $[178,179]$.

Recently, Poly (ADP-ribose) polymerase (PARP) inhibitors have stimulated much excitement. PARP-1 is a member of the PARP enzyme family and is one of the most abundant nuclear proteins which functions as a DNA-nick-sensor enzyme [180]. Research conducted by Du et al. [181] revealed that hyperglycemia-induced overproduction of superoxide by the mitochondrial electron transport chain activates the three major pathways of hyperglycemic damage found in aortic endothelial cells by inhibiting GAPDH (glyceraldehyde-3-phosphate dehydrogenase) activity. Thus, inhibition of PARP blocks hyperglycemia-induced activation of multiple pathways of vascular damage and provides a unique approach as it blocks activation of all the major pathways thought to mediate tissue damage in diabetes.

\section{Metabolic modulators}

Metabolic modulators are a newer class of drugs that benefit patients by modulating cardiac metabolism without altering hemodynamics. They have the potential to relieve symptoms in patients with refractory heart failure who are already on optimal medical therapy. These drugs increase glucose metabolism at the expense of free fatty acid metabolism, thereby enhancing efficient use of oxygen. Three metabolic modulators drugs that could potentially 
be used for HF therapy and CDM are: trimetazidine, resveratrol and ranolazine.

Trimetazidine, a competitive inhibitor of the terminal enzyme in $\beta$-oxidation has promising beneficial effects on heart failure in diabetic patients with both idiopathic and ischemic dilated cardiomyopathy [182]. Studies of animal models revealed that trimetazidine reduce free radical injury, improve endothelial function, inhibit apoptosis and attenuate lipotoxicity [183]. However, human trials are needed to investigate the beneficial effects of this drug on the treatment and prevention of DCM. Studies on resveratrol revealed that it reduces glucose levels; improve triglyceride level, heart rate, and glycemia [184] while ranolazine, a potent late $\mathrm{Na}^{+}$current inhibitor, normalize altered cardiomyocyte intracellular calcium concentration due to the close relationship between $\mathrm{Ca}^{2+}$ and $\mathrm{Na}^{+}$handling by the $\mathrm{Na}^{+} / \mathrm{Ca}^{2+}$ exchanger [186].

\section{New therapeutic directions}

Within the past five years, research into new therapeutic direction focused on the areas of cell/genetic therapy and targeting mitochondrial oxidative stress. A few of these new emerging treatment modalities will be discussed in this section. An excellent review on this topic was done by Huynk et al. [186] in which they discussed both conventional and novel therapeutic approaches for the treatment of left ventricular dysfunction in diabetic patients.

mi-RNA.

The dysregulation of micro-ribonucleic acid (mi-RNA) function serve as an important pathogenic mechanism of diabetes and its complications. mi-RNAs have been reported to be potential biomarker for early detection of DCM and they have become the subject of an active area of research to establish their potential contribution to heart disease in patients with T2DM. The noncoding RNA, miR-223 was found to be associated with regulation of GLUT4 expression in adult cardiomyocytes [187] while data from experimental studies underscore the contribution of miR-21 in stimulating MAP kinase signaling in mouse fibroblasts, consequently promoting fibrosis and contractility alterations as features of DCM in diabetic animal models $[188,189]$. Other research have implicated miRNA to be involved in regulating extracellular signal regulated kinases (ERK) in diabetic conditions and therefore, modulating ERK1/2 derived-pathway which opposes oxidative stress-induced insulin resistance in cardiomyocytes [190]. 
Coenzyme Q10.

Recent research by Mortensen et al. [191], on the effect of coenzyme Q10 on morbidity and mortality in chronic heart failure patients using randomized controlled trial, showed that long-term coenzyme Q10 treatment in patients with chronic heart failure is safe, improves symptoms, and reduces all-cause mortality by $42 \%$ and cardiovascular death by $43 \%$. Other reports have also established that coenzyme Q10 improves cardiac function in patients with DM and concurrent heart failure [192,193].

Pim-1.

Pim-1 (serine/threonine-protein kinase pim-1) gene therapy was shown to improve LV diastolic function, prevent cardiac apoptosis, fibrosis, and development of HF [194]. While in other studies [195], it was demonstrated that Pim-1 downregulation contributes in the pathogenesis of diabetic cardiomyopathy. Thus, establishing that intravenous gene therapy with pim-1 via a cardiotropic viral vector halts the progression of diabetic cardiomyopathy through promotion of pro-survival signaling and represents a novel and effective approach to treat the disease.

Phosphoinositide 3-kinase.

In a very recent research, Prakoso and colleagues [196] investigated the therapeutic potential of a delayed intervention with cardiac-targeted phosphoinositide 3-kinase (PI3K) gene therapy, administered to mice with established diabetes-induced LV diastolic dysfunction. After study endpoint, it was discovered that diabetes-induced LV dysfunction was significantly attenuated by a single administration of recombinant adeno-associatedvirus 6-constitutively active PI3K ( $1110 \alpha)$ (rAAV6-caPI3K), administered 8 weeks after the induction of diabetes. Their results clearly demonstrate that cardiac-targeted PI3K (p110 $\alpha$ ) gene therapy limits diabetes-induced up-regulation of NADPH oxidase and cardiac remodelling suggests new insights into promising approaches for the treatment of diabetic cardiomyopathy.

Szeto-Schiller peptide.

The SS (Szeto-Schiller) peptide antioxidants represent a novel approach with targeted delivery of antioxidants to the inner mitochondrial membrane. The structural motif of these SS peptides centers on alternating aromatic residues and basic amino acids (aromaticcationic peptides). These SS peptides can scavenge hydrogen peroxide and peroxynitrite and 
inhibit lipid peroxidation. By reducing mitochondrial ROS, these peptides inhibit mitochondrial permeability transition and cytochrome $c$ release, thus preventing oxidantinduced cell death [197].

The Szeto-Schiller peptide d-Arg-2', 6'-dimethyltyrosine-Lys-Phe-NH2 (SS31) is a positively charged free-radical scavenger that can accumulate to high levels in the mitochondria and prevent diastolic dysfunction, fibrosis, and cardiac hypertrophy [192].

This technique represents a promising approach for preventing DCM by targeting excess myocardial ROS with novel antibiotics.

\section{Conclusion}

The prevalent rise in DM worldwide has made DCM an increasing health concern. As the incidence and prevalence of DM continue to rise, HG-induced structural and ultrastructural changes may cause a reduction in heart perfusion and eventually HF. A variety of treatment options have shown to be effective in treating DCM and novel therapeutic strategies, such as gene therapy targeting the phosphoinositide 3-kinase PI3K (p110 $\alpha)$, signaling pathway, and miRNA dysregulation have shown good promise. In addition to these, targeting redox stress and mimetic peptides targeting calcium channels may represent a future strategy for combating the ever-increasing incidence of heart failure in the diabetic population.

Acknowledgements None.

Conflict of interests None.

\section{References}

1. Jacobsen IB, Henriksen JE, Hother-Nielsen O, Vach W, Beck-Nielsen H (2009) Evidencebased insulin treatment in type 1 diabetes mellitus. Diab Res Clinic Pract 86:1-10

2. American Diabetes Association (2009) Diagnosis and Classification of Diabetes Mellitus. Diabetes Care. 32 (Suppl 1): S62-S67.

3. Pereira L, Matthes J, Schuster I, Valdivia HH, Herzig S, Richard S, Gomez AM (2006) 
Mechanisms of $\left[\mathrm{Ca}^{2+}\right]_{i}$ transient decrease in cardiomyopathy of $\mathrm{db} / \mathrm{db}$ type 2 diabetic mice. Diabetes. 55:608-615.

4. Schafer SA, Machicao F, Fritsche A, Häring HU, Kantartzis K (2011) New type 2 diabetes risk genes provide new insights in insulin secretion mechanisms. Diabetes Res Clin Pract. 93(Suppl 1): S9-24.

5. An D, Rodrigues B (2006) Role of changes in cardiac metabolism in development of diabetic cardiomyopathy. Am J Physiol Heart Circ Physiol. 291:H1489-1506.

6. Long A, Jack SD (2011) The Comorbidities of Diabetes and Hypertension: Mechanisms and Approach to Target Organ Protection. J Clin Hypertens (Greenwich). 13 (4): 244251. DOI: $10.1111 / j .1751-7176.2011 .00434 . x$

7. NCD Risk Factor Collaboration (2016) Worldwide trends in diabetes since 1980: a pooled analysis of 751 population-based studies with 4.4 million participants. Lancet. 387: 1513-1530.

8. Anand SS, Yusuf S (2011) Stemming the global tsunami of cardiovascular disease. Lancet. 377:529-532.

9. Singh RM, Cummings E, Pantos C, Singh J (2017) Protein kinase C and cardiac dysfunction: a review. Heart Fail Rev. 22: 843-859. DOI: 10.1007/s10741-017-9634-3.

10. Pappachan JM, Varughese GI, Sriraman R, Arunagirinathan G (2013) Diabetic cardiomyopathy: pathophysiology, diagnostic evaluation and management. World J Diabetes. 4: 177-189.

11. Kannel WB, McGee DL. Diabetes and cardiovascular disease: the Framingham study. (1979) JAMA. 241:2035-2038.

12. Lee WS, Kim J (2017) Diabetic cardiomyopathy: where we are and where we are going. Korean J Intern Med. 32:404-421

13. Isfort M, Stevens SCW, Schaffer S, Jong CJ, Wold LE (2014) Metabolic Dysfunction in Diabetic Cardiomyopathy. Heart Fail Rev. 19(1): 9377-9388.

14. Aneja A, Tang WH, Bansilal S, Garcia MJ, Farkouh ME (2008) Diabetic cardiomyopathy: insights into pathogenesis, diagnostic challenges, and therapeutic options. Am J Med. 121:748-757.

15. Gilca, GM, Stefanescu G, Badulescu O, Tanase DM, Bararu I, Ciocoiu M (2017) Diabetic Cardiomyopathy: Current Approach and Potential Diagnostic and Therapeutic Targets. J Diabetes Res. DOI: 10.1155/2017/1310265.

16. Wang ZV, Hill JA (2015) Diabetic cardiomyopathy: catabolism-driving metabolism. Circ. 
131:771-773.

17. Boudina S, Abel ED (2007) Diabetic cardiomyopathy revisited. Circ. 115:3213-3223.

18. Belke DD, Larsen TS, Gibbs EM, Severson DL (2000) Altered metabolism causes cardiac dysfunction in perfused hearts from diabetic $(\mathrm{db} / \mathrm{db})$ mice. Am J Physiol Endocrinol Metab. 279: E1104-E1113.

19. Bhimji S, Godin DV, McNeill JH (1986) Myocardial ultrastructural changes in alloxaninduced diabetes in rabbits. Acta Anat (Basel). 125: 195-200.

20. Forsterman U, Munzel T (2006) Endothelial nitric oxide synthase in vascular disease: from marvel to menace. Circ. 113:1708-1714.

21. Jia G, DeMarco VG, Sowers JR (2016) Insulin resistance and hyperinsulinaemia in diabetic cardiomyopathy. Nat Rev Endocrinol. 12:144-153.

22. Nishikawa T, Edelstein D, Du XL, Yamagishi S, Matsumura T, Kaneda Y, Yorek MA, Beebe D, Oates PJ, Hammes HP, Giardino I,Brownlee M (2000) Normalizing mitochondrial superoxide production blocks three pathways of hyperglycaemic damage. Nature. 404: 787-790.

23. Choi SW, Benzie IF, Ma SW, Strain JJ, Hannigan BM (2008) Acute hyperglycaemia and oxidative stress: Direct cause and effect? Free Rad Bio and Med. 44: 1217-1231.

24. Borradaile NM, Han X, Harp JD, Gale SE, Ory DS, Schaffer JE (2006) Disruption of endoplasmic reticulum structure and integrity in lipotoxic cell death. J Lipid Res 47:2726-2737.

25. Lebeche D, Davidoff AJ, Hajjar RJ (2008) Interplay between impaired calcium regulation and insulin signaling abnormalities in diabetic cardiomyopathy. Nat Clin Pract Cardiovasc Med. 5:715-724.

26. Minamino T, Komuro I, Kitakaze M (2010) Endoplasmic reticulum stress as a therapeutic target in cardiovascular disease. Circ Res. 107(9): 1071-1082.

27. Brownlee M (2001) Biochemistry and molecular cell biology of diabetic complications. Nature 414: 813-820.

28. Nishikawa T, Edelstein D, Brownlee M (2000) The missing link: a single unifying mechanism for diabetic complications. Kidney Int Suppl. 77:S26-S30.

29. Robertson RP (2004) Chronic oxidative stress as a central mechanism for glucose toxicity in pancreatic islet beta cells in diabetes. J Biol Chem. 279:42351-42354.

30. Choi YS, Kim S, Pak YK (2001) Mitochondrial transcription factor A (mtTFA) and diabetes. Diabetes Res Clin Pract. 54, Suppl 2: S3-S9. 
31. Kanazawa A, Nishio Y, Kashiwagi A, Inagaki H, Kikkawa R, Horiike K (2002) Reduced activity of mtTFA decreases the transcription in mitochondria isolated from diabetic rat heart. Am J Physiol Endocrinol Metab. 282: E778-E785.

32. Bishop SP, Altschuld RA (1970) Increased glycolytic metabolism in cardiac hypertrophy and congestive failure. Am J Physiol 218(1): 153-159.

33. Herrero P, Peterson LR, McGill JB, Matthew S, Lesniak D, Dence C, Gropler RJ (2006) Increased myocardial fatty acid metabolism in patients with type 1 diabetes mellitus. J Am Coll Cardiol. 47(3): 598-604.

34. Young ME, Guthrie PH, Razeghi P, Leighton B, Abbasi S, Patil S.,Youker KA, Taegtmeyer H (2002) Impaired long-chain fatty acid oxidation and contractile dysfunction in the obese Zucker rat heart. Diabetes. 51(8): 2587-2595.

35. Finck BN, Lehman JJ, Leone TC, Welch MJ, Bennett MJ, Kovacs A, Han X, Gross RW, Kozak R, Lopaschuk GD, Kelly DP (2002) The cardiac phenotype induced by PPARalpha overexpression mimics that caused by diabetes mellitus. J Clin Invest. 109(1): 121-130.

36. Awan MM, Saggerson ED (1993) Malonyl-CoA metabolism in cardiac myocytes and its relevance to the control of fatty acid oxidation. Biochem J. 295(Pt 1): 61-66.

37. Stanley WC, Lopaschuk GD, McCormack JG (1997) Regulation of energy substrate metabolism in the diabetic heart. Cardiovasc Res. 34(1): 25-33.

38. Huang B, Wu P, Popov KM, Harris RA (2003) Starvation and diabetes reduce the amount of pyruvate dehydrogenase phosphatase in rat heart and kidney. Diabetes. 52(6): 13711376.

39. Randle PJ, Garland PB, Hales CN, Newsholme EA, Denton RM, Pogson Cl (1966) Interactions of metabolism and the physiological role of insulin. Recent Prog Horm Res. 22:1-48.

40. Neely JR, Morgan HE (1974) Relationship between carbohydrate and lipid metabolism and the energy balance of heart muscle. Annu Rev Physiol. 36:413-459.

41. Sambandam N, Lopaschuk GD. (2003) AMP-activated protein kinase (AMPK) control of fatty acid and glucose metabolism in the ischemic heart. Prog Lipid Res. 42:238-256.

42. Schaffer SW, Seyed-Mozaffari M, Cutcliff CR, Wilson GL (1986) Postreceptor myocardial metabolic defect in a rat model of non-insulin-dependent diabetes mellitus. Diabetes. 35: 593-597.

43. Bowman RH (1966) Effects of diabetes, fatty acids, and ketone bodies on tricarboxylic acid cycle metabolism in the perfused rat heart. J Biol Chem. 241:3041-3048. 
44. Kuo TH, Moore KH, Giacomelli F, Wiener J (1983) Defective oxidative metabolism of heart mitochondria from genetically diabetic mice. Diabetes. 32:781-787.

45. Pierce GN, Dhalla NS (1985) Heart mitochondrial function in chronic experimental diabetes in rats. Can J Cardiol. 1:48-54.

46. Tomita M, Mukae S, Geshi E, Umetsu K, Nakatani M, Katagirl T (1996) Mitochondrial respiratory impairment in streptozotocininduced diabetic rat heart. Jpn Circ J 60:673682.

47. Boudina S, Sena S, O'Neill BT, Tathireddy P, Young ME, Abel ED (2005) Reduced mitochondrial oxidative capacity and increased mitochondrial uncoupling impair myocardial energetics in obesity. Circ. 112:2686-2695.

48. Suarez J, Hu Y, Makino A, Fricosky E, Wang H, Dillmann WH (2008) Alterations in mitochondrial function and cytosolic calcium induced by hyperglycemia are restored by mitochondrial transcription factor A in cardiomyocytes. Am J Physiol Cell Physiol. 295:C1561-1568.

49. Rogers TB, S. T. Gaa ST, Massey C, Dosemeci A (1990) Protein kinase C inhibits Ca21 accumulation in cardiac sarcoplasmic reticulum. J. Biol. Chem. 265: 4302-4308.

50. Noland TA, Jr, and Kuo, JF (1991) Protein kinase C phosphorylation of cardiac troponin I or troponin T inhibits $\mathrm{Ca}^{2+}$-stimulated actomyosin MgATPase activity. J. Biol. Chem. 266: 4974-4978.

51. Malhotra A, Reich D, Nakouzi A, Sanghi V, Geenen DL, Buttrick PM (1997) Experimental diabetes is associated with functional activation of protein kinase $C$ and phosphorylation of troponin I in the heart, which are prevented by angiotensin II receptor blockade. Circ. Res. 81: 1027-1033.

52. Liu X, Takeda N, Dhalla, NS (1996) Troponin I phosphorylation in heart homogenate from diabetic rat. Biochim. Biophys. Acta. 1316: 78-84.

53. Okumura K, Akiyama N, Hashimoto H, Ogawa K, Satake T (1988) Alteration of 1,2,diacylglycerol content in myocardium from diabetic rats. Diabetes. 37: 1168-1172.

54. Liu X, Wang J, Nobuakira T, Binaglia L, Panagia V, Dhalla NS (1999) Changes in cardiac protein kinase $\mathrm{C}$ activities and isozymes in streptozotocin-induced diabetes. Am. J. Physiol. 277 (Endocrinol. Metab. 40): E798-E804.

55. Isfort M, Stevens SCW, Schaffer S, Jong CJ, Wold LE (2014) Metabolic Dysfunction in Diabetic Cardiomyopathy. Heart Fail Rev. 19(1): DOI:10.1007/s10741-013-9377-8.

56. Lopaschuk GD, Ussher JR, Folmes CDL, Jaswal JS, Stanley, WC (2010) Myocardial Fatty 
Acid Metabolism in Health and Disease. Physiol Rev. 90: 207-258.

57. Mortuza R, Chakrabarti S (2014) Glucose-induced cell signalling in the pathogenesis of diabetic cardiomyopathy. Heart Fail Rev. 19: 75-86.

58. Dhalla NS, Takeda N, Rodriguez-Leyva D, Elimban V (2014) Mechanisms of subcellular remodeling in heart failure due to diabetes. Heart Fail. Rev.19: 87-99. DOI: 10.1007/s10741-013-9385-8.

59. Dhalla NS, Liu X, Panagia V, Takeda N (1998) Subcellular remodelling and heart dysfunction in chronic diabetes. Cardiovasc Res. 40(2): 239-247.

60. Brownlee M (2005) The Pathobiology of diabetic complications: a unifying mechanism. Nature. 54:1615-1625.

61. Doron A (2003) Cross-linking of glycated collagen in the pathogenesis of arterial and myocardial stiffening of ageing and diabetes. J Hyperten. 21:3-12.

62. Asbun J, Villareal FJ (2006) The pathogenesis of myocardial fibrosis in the setting of diabetic cardiomyopathy. J Am Coll Cardiol. 47:693-700.

63. Masoudi FA, Inzucchi SE (2007) Diabetes mellitus and heart failure: epidemiology, mechanisms, and pharmacotherapy. Am J Cardiol. 99:113-132.

64. Giacco F, Brownlee M (2010) Oxidative stress and diabetic complications. Circ Res. 107:1058-1070.

65. Scott JA, King GL (2004) Oxidative stress and antioxidant treatment in diabetes. Ann. N. Y. Acad. Sci. 1031:204-213.

66. Boudina S, Abel ED (2010) Diabetic cardiomyopathy, causes and effects. Rev Endocr Metab Disord. 11:31-39.

67. Dobrin JS, Lebeche D (2010) Diabetic cardiomyopathy: signalling defects and therapeutic approaches. Exp Rev Cardiovasc Ther. 8:373-391.

68. Candido R, Forbes JM, Thomas MC, Thallas V, Dean RG, Burns WC, Tikellis C, Ritchie RH, Twigg SM, Cooper ME, burrell LM (2003) A breaker of advanced glycation end products attenuates diabetes-induced myocardial structural changes. Circ Res. 92:785-792.

69. Young LH, Wackers FJ, Chyun DA, Davey JA, Barrett EJ, Taillefer R, Heller GV, Iskandrian AE, Wittlin SD, Filipchunk N, Ratner RE, Inzucchi SE (2009) DIAD Investigators. Cardiac outcomes after screening for asymptomatic coronary artery disease in patients with type 2 diabetes: the DIAD study, a randomized controlled trial. JAMA. 301:1547-1555. 
70. Cai L, Wang Y, Zhou G, Chen T, Li X, Kang YJ (2006) Attenuation by metallo-thionein of early cardiac cell death via suppression of mitochondrial oxidative stress results in a prevention of diabetic cardiomyopathy. J Am Coll Cardiol. 48:1688-1697.

71. Guo Z, Xia Z, Jiang J, McNeil JH (2007) Down-regulation of NADPH oxidase, antioxidant enzymes and inflammatory markers in the heart of streptozotocin-induced diabetic rats by N enzymes. Am J Physiol Heart Circ Physiol. 292:H1728-H1736.

72. Schleicher ED, Weigert C (2000) Role of the hexosamine biosynthetic pathway in diabetic nephropathy. Kidney Intern. 58:S-13-S-18.

73. Mohora M, Greabu M, Muscurel C, Duta C, Totan A (2007) The sources and the targets of oxidative stress in the aetiology of diabetic complications. Romanian J. Biophysics. $17: 63-84$.

74. Belke DD, Dillmann WH (2004) Altered cardiac calcium handling in diabetes. Curr Hypertens Rep. 6:424-429.

75. Woodcock EA \& Matkovich SJ (2005) Cardiomyocytes structure, function and associated pathologies. The Inter J Biochem \& Cell Bio. 37:1746-1751.

76. Roderick HL, Bootman MD (2007) Pacemaking, arrhythmias, inotropy and hypertrophy: the many possible facets of IP3 signalling in cardiac myocytes. J Physiol. 581 (3): 883884.

77. Bers DM, Eisner DA, Valdivia HH (2003) Sarcopalsmic Reticulum Ca ${ }^{2+}$ Transport and Heart Failure: Roles of Diastolic Leak and $\mathrm{Ca}^{2+}$ Circ Res. 93:487-490.

78. Hilgemnn DW (2004) New insights into the molecular and cellular workings of the cardiac Na+/Ca2+ exchanger. Am J Physiol Cell Physiol. 287(5): C1167-1172.

79. Mackrill JJ (2010) Ryanodine receptor calcium channels and their partners as drug targets. Biochem Pharmacol: 79 1535-1543.

80. Kushnir AA, Betzenhauser MJ, Marks AR (2010) Ryanodine receptor studies using genetically engineered mice. FEBS Lett. 584:1956-1965.

81. Hasenfuss $G$ and Schillinger W (2004) Is Modulation of Sodium-Calcium Exchange a Therapeutic Option in Heart Failure? Circ Res. 95:225-227.

82. Franzini-Armstrong, C (1970) Studies of the triad. J Cell Biol. 47: 488-499.

83. Campbell K, Franzini-Armstrong C, Shamoo A (1980) Further characterisation of light and heavy sarcoplasmic reticulum vesicles. Identification of the 'sarcoplasmic reticulumfeet' associated with heavy sarcoplasmic reticulum-vesicles. Biochem Biophys Acta. 602: 97-116. 
84. Lai FA, Anderson K, Rousseau E, Liu QY, Meissner G (1988). Evidence for a Ca2+ channel within the ryanodine receptor complex from cardiac sarcoplasmic reticulum. Biochem Biophys Res Commun. 151:441-449.

85. Takeshima H, Nishimura S, Matsumoto, T, Ishida H, Kangawa K, Minamino N, Matsuo H, Ueda M, Hanaoka M, Hirose T (1989) Primary structure and expression from complementary DNA of skeletal muscle ryanodine receptor. Nature. 339:439-445.

86. Zorzato F, Fujii J, Otsu K, Phillips M, Green NM, Lai FA, Meissner G, Maclennan DH (1990) Molecular cloning of cDNA encoding human and rabbit forms of the $\mathrm{Ca}^{2+}$ release channel (ryanodine receptor) of skeletal muscle sarcoplasmic reticulum. J Biol Chem. 265:2244-2256.

87. Tunwell RE, Wickenden C, Bertrand BM, Shevchenko VI, Walsh MB, Allen PD, Lai, FA (1996) The human cardiac muscle ryanodine receptor-calcium release channel: identification, primary structure and topological analysis. Biochem J. 318:477-487.

88. Hakamata Y, Nakai J, Takeshima H, \& Imoto K (1992) Primary structure and distribution of a novel ryanodine receptor/calcium release channel from rabbit brain. FEBS Lett. 312: 229-235.

89. Hillyard, I. and Procia, L (1956) Action of ryanodine on isolated kitten auricle. Fed. Proc. 15:438-449.

90. Meissner, G (1986) Ryanodine activation and inhibition of the $\mathrm{Ca}^{2+}$ release channel of sarcoplasmic reticulum. J Biol Chem. 261:6300-6306.

91. Bers DM, Eisner DA, Valdivia, HH (2003) Sarcoplasmic reticulum $\mathrm{Ca}^{2+}$ and heart failure: roles of diastolic leak and $\mathrm{Ca}^{2+}$ transport. Circ Res. 93:487-490.

92. Priori SG, Napolitano C, Tiso N, Memmi M, Vignati G, Bloise R, Sorrentino V, Danieli GA (2001) Mutations in the cardiac ryanodine receptor gene (hRyR2) underlie catecholaminergic polymorphic ventricular tachycardia. Circ .103:196-200.

93. George CH, Jundi H, Thomas NL, Fry DL, Lai FA (2007) Ryanodine receptors and ventricular arrhythmias: emerging trends in mutations, mechanisms and therapies. J Mol Cell Cardiol. 42:34-50.

94. Ganguly PK, Pierce GN, Dhalla KS, Dhalla NS (1983) Defective sarcoplasmic reticular calcium transport in diabetic cardiomyopathy. Am J Physiol. 244: E528-E535.

95. Pierce GN, Ramjiawan B, Dhalla NS, Ferrari R (1990) $\mathrm{Na}^{+}-\mathrm{H}^{+}$exchange in cardiac sarcolemmal vesicles isolated from diabetic rats. Am J Physiol. 258: $\mathrm{H} 255-\mathrm{H} 261$.

96. Makino N, Dhalla KS, ElimbanV, Dhalla NS (1987). Sarcolemmal Ca ${ }^{2+}$ transport in 
streptozotocin-induced diabetic cardiomyopathy in rats. Am J Physiol. 253: E202-E207.

97. Lun SL, Ostadalova I, Kolar, Dhalal NS (1992) Alterations in $\mathrm{Ca}^{2+}$-channels during the development of diabetic cardiomyopathy. Mol Cell Biochem .109 (2): 173-179.

98. Dhalla NS, Rangi S, Zieroth S, Xu YJ (2012) Alterations in sarcoplasmic reticulum and mitochondrial functions in diabetic cardiomyopathy. Exp Clin Cardiol. 17(3): 115-120.

99. Okunade GW, Miller ML, Pyne GJ, Sutliff RL, O’Connor KT, Neumann JC, Andringa A, Miller DA, Prasad V, Doetschman T, Paul RJ, Shull GE (2004) Targeted ablation of plasma membrane Ca2+-ATPase (PMCA) 1 and 4 indicates a major housekeeping function for PMCA1 and a critical role in hyperactivated sperm motility and male fertility for PMCA4. J Biol Chem. 279:33742-33750.

100. Orio P, Rojas P, Ferreira G, and Latorre R (2002) New disguises for an old channel: MaxiK channel -subunits. News Physiol Sci. 17:156-161.

101. Liu N, Colombi B, Memmi M, Zissimopoulos S, Rizzi N, Imbriani M, Napolitano C, Lai FA, Priori SG (2006) Arrhythmogenesis in catecholaminergic polymorphic ventricular tachycardia: insights from a RyR2 R4496C knock-in mouse model. Circ Res 99:292-298.

102. Periasamy M \& Huke S (2001) SERCA Pump Level is a Critical Determinant of $\mathrm{Ca}^{2+}$ Homeostasis and Cardiac Contractility. J Mol Cell Cardiol. 33: 1053-1063.

103. Searls YM, Loganathan R, Smirnova IV, Stehno-Bittel L (2010) Intracellular Ca ${ }^{2+}$ regulating proteins in vascular smooth muscle cells are altered with type 1 diabetes due to the direct effects of hyperglycemia. Cardiovasc Diabetol. 9(8): DOI: 10.1186/1475/-2840-9-8.

104. Abe T, Ohga $\mathrm{Y}$, Tabayashi N, Kobayashi S (2002) Left ventricular diastolic dysfunction in type II diabetes mellitus model rats. Am J Heart Circ Physiol. 282:H139-H148.

105. Wold LE, Dutta K, Mason MM, Ren J, Cala SE, Schwanke ML, Davidoff AJ (2005) Impaired SERCA function contributes to cardiomyocyte dysfunction in insulin resistant rats. J Mol Cell Cardiol. 39:297-307.

106.Zarain-Herzberg A, Yano K, Elimban V, Dhalla NS (1994) Cardiac sarcoplasmatic reticulum $\mathrm{Ca}^{2+}-$ ATPase expression in streptozotocin-induced diabetic rat. Biochem Biophys Res Comm. 203:113-120.

107.Zhong Y, Ahmed S, Grupp IL, Matlib MA (2001) Altered SR protein expression associated with contractile dysfunction in diabetic rat heart. Am J Physiol Heart Circ Physiol. 281:H1137-H1147. 
108. Aoyagi T, Yonekura K, Eto Y, Matsumoto A, Yokoyama I, Sugiura S, Momomura S, Hirata Y, Baker DL, Periasamy M. (1999) The Sarcoplasmic reticulum Ca ${ }^{2+}$ ATPase gene promoter activity is decreased in response to severe left ventricular pressure- overload in hypertrophy rats. J Moll Cell Cardiol. 31:919-916.

109. Connelly KA, Gilbert RE, Krum H (2007) Letter by Connelly et al regarding article, "Diastolic stiffness of the failing diabetic heart: importance of fibrosis, advanced glycation end products, and myocyte resting tension". Circ. 117 (23) e483; author reply e484

110. Fredersdorf S, Thumann C, Zimmerman WH, Vetter R, Graf T, Luchner A, Riegger GA, Schunkert H, Eschenhagen T, Weil J (2012) Increased myocardial SERCA expression in early type 2 diabetes mellitus is insulin dependent: In vivo and in vitro data. Cardiovas Diabetol. 11(57): 1-11.

111. Lacombe K, Massari V, Girard P, Serfaty L, Gozlan J, Pialoux G, Mialhes P, Molina JM, Lascoux-Combe C, Wendum D, Carrat F, Zoulim F (2006) Major role of hepatitis B genotypes in liver fibrosis during coinfection with HIV. AIDS. 20: 419-427.

112.Zhong Y, Ahmed S, Grupp IL, Matlib MA (2001) Altered SR protein expression associated with contractile dysfunction in diabetic rat heart. Am J Physiol Heart Circ Physiol. 281:H1137-H1147.

113. Dhalla NS, Liu X, Panagia V, Takeda N (1998) Subcellular remodeling and heart dysfunction in chronic diabetes. Cardiovasc Res. 40(2): 239-47.

114. Dhalla NS, Temsah RM, Netticadan T (2000) Role of oxidative stress in cardiovascular diseases. J Hypertens. 18: 655-73.

115. Bracken NK, Singh J, Winlow W, Howarth FC (2003) Mechanism underlying contractile dysfunction in streptozotocin-induced type 1 and type 2 diabetic cardiomyopathy. In: Pierce G.N., Nagano M., Zahradka P., Dhalla N.S. (eds) Atherosclerosis, Hypertension and Diabetes. Progress in Experimental Cardiology, vol 8. Springer, Boston, MA, pp387408.

116. Howarth FC, Singh J (1999) Altered handling of calcium during the process of excitation-contraction coupling in the streptozotocin-induced diabetic heart: a short review Int J Diab. 7:52-64.

117. Pandit SV, Giles WR, Demir SS (2003) A mathematic model of the electrophysiological alterations in rat ventricular myocyte in type 1 diabetes mellitus. Biophys J. 84:832841. 
118. Howarth FC, Qureshi MA, Bracken NK, Winlow W, Singh J (2001) Time dependant effects of streptozotocin-induced diabetes on contraction in rat ventricular myocytes. Emirates J 19:25-41.

119. Singh J, Chonkar A, Bracken N, Adeghate E, Latt Z, Hussain M (2006) Effect of streptozotocin-induced type 1 diabetes mellitus on contraction, calcium transient, and cation contents in the isolated rat heart. Ann N Y Acad Sci. 1084:178-190.

120. Sheikh AQ, Hurley JR, Huang W, Taghian T, Kogan A, Cho Hongkwan, Wang Y (2012) Diabetes Alters Intracellular Calcium Transients in Cardiac Endothelial Cells. PLoS ONE. 7(5): e36840

121. Belke DD, Swanson EA, Dillmann WH (2004) Decreased Sarcoplasmic Reticulum Activity and Contractility in Diabetic db/db Mouse Heart. Diabetes. 53:3201-3208

122. Salem KA, Qureshi MA, Sydorenko V, Iqbal T, Singh, J, Howarth, C (2013) Effects of exercise training on excitation-contraction coupling and related mRNA expression in hearts of Goto-Kakizaki type 2 diabetic rats. Molec Cell Biochem. 380(1-2): 83-96.

123. Zhang H, Chen X, Gao E, MacDonnell SM, Wang W, Kolpakov M, Nakayama H, Zhang X, Jaleel N, Harris DM, Li Y, Tang M, Berretta R, Leri A, Kajstura J, Sabri A, Koch WJ, Molkentin JD, Houser SR. (2010) Increasing Cardiac contractility after myocardial infarction exacerbates cardiac injury and pump dysfunction. Circ Res. 107:800-809. DOI: 10.1161/CIRCRESAHA.110.219220.

124. Nemoto O, Kawaguchi M, Yaoita H, Miyake K, Maehara K, Maruyama Y (2006) Left ventricular dysfunction and remodeling in streptozotocin-induced diabetic rats. Circ J. 70:327-334.

125. D'Souza A, Howarth FC, Yanni J, Dobryznski H, Yanni J, Dobryznski H, Boyett MR, Adeghate E, Bidasee KR, Singh J (2011) Left ventricle structural remodelling in the prediabetic Goto-Kakizaki rat. Exp Physiol. 96(9): b875-88.

126. Kitzman DW, Higginbotham MB, Cobb FR, Sheikh Sullivan MJ (1991) Exercise intolerance in patients with heart failure and preserved left ventricular systolic function: failure of the Frank-Starling mechanism. J Am Coll Cardiol 17:1065-1072.

127. Gandhi SK, Powers JC, Nomeir AM, Fowle K, Kitzman DW, Rankin KM, Little WC (2001) The pathogenesis of acute pulmonary oedema associated with hypertension. N Engl J Med. 344:17-22.

128. Vasan RS, Larson MG, Benjamin EJ, Evans JC, Reiss CK, Levy D (1999) Congestive heart failure in subjects with normal versus reduced left ventricular ejection fraction: 
prevalence and mortality in a population based cohort. J Am Coll Cardiol. 33:1948 1955.

129. Pieske B, Wachter R (2008) Impact of diabetes and hypertension on the heart. Curr Opin Cardiol. 23:340 -349.

130. Ren X, Ristow B, Na B, Ali S, Schiller NB, Whooley MA (2007) Prevalence and prognosis of asymptomatic left ventricular diastolic dysfunction in ambulatory patients with coronary heart disease. Am J Cardiol. 99:1643-1647.

131. Iribarren C (2001) Glycemic control and heart failure among adult patients with diabetes. Circ. 103:2668-2673.

132. Bertoni AG, Hundley WG, Massing MW, Bonds DE, Burke GL, Goff DC Jr. (2004) Heart Failure Prevalence, Incidence, and Mortality in the Elderly With Diabetes, Diab Car. 27: 344-348.

133. Burkhoff D (2012) Mortality in heart failure with preserved ejection fraction: an unacceptably high rate, Euro Heart J. 33:1718-1720.

134. MacDonald MR, Petrie MC, Varyani F Ostergren J, Michelson EL, Young JB, Solomon SD, Granger CB, Swedberg K, Yusuf S, Pfeffer MA, McMurray JJ (2008) Impact of diabetes on outcomes in patients with low and preserved ejection fraction heart failure. Europ Heart J. 29:1377-1385.

135. Poirier, P Bogaty P, Garneau C, Marois L, Dumesnil JG (2001) Diastolic dysfunction in normotensive men with well-controlled type 2 diabetes: importance of manoeuvers in echocardiographic screening for preclinical diabetic cardiomyopathy. Diabetes Care. 24: 1-5.

136. Andersen NH, Poulsen SH, Helleberg K, Ivarsen P, Knudsen ST, Mogensen CE (2003) Impact of Essential Hypertension and Diabetes Mellitus on Left Ventricular Systolic and Diastolic Performance. Eur J Echocardiography. 4:306-312.

137. Magri CJ, Cassar A, Fava S, Felice H (2012) Heart Failure with Preserved Ejection Fraction and Diabetes Mellitus. J of Diab Res and Clinic Metab. DOI: 10.7243/20500866-1-2.

138. EhI NF, Kuhne M, Brinkert M, Muller-Brand J, Zellweger MJ (2011) Diabetes reduces left ventricular ejection fraction-irrespective of presence and extent of coronary artery disease, Euro J of Endocrinol. 165: 945-951. 
139. Wong CY, O'Moore-Sullivan T, Leano R, Byrne, Beller E, Marwick TH (2004) Alterations of left ventricular myocardial characteristics associated with obesity. Circ. 110:30813087.

140. Heerebeek VL, Hamdani N, Handoko ML, Falcao-Pires I, Musters RJ, Kupreishvili K, Ijsselmuiden AJ, Schalkwijk CG, Bronzwaer JG, Diamant M, Borbély A, van der Velden J, Stienen GJ, Laarman GJ, Niessen HW, Paulus WJ (2008) Diastolic stiffness of the failing diabetic heart. Importance of fibrosis, advanced glycation end products, and myocyte resting tension. Circ. 117:43-51.

141. Borlaug BA, Lam CSP, Roger VL, Rodeheffer RJ, Redfield MM (2009) Contractility and Ventricular Systolic Stiffening in Hypertensive Heart Disease, J Am Coll Cardiol. 54:410418.

142. Maeder MT and Kaye DM (2009) Heart Failure With Normal Left Ventricular Ejection Fraction, J Am Coll Cardiol. 53:11-16.

143. Periasamy M, and Janssen ML (2008) Molecular Basis of Diastolic Dysfunction. Heart Fail Clin. 4(1): 13-21.

144. Aurigemma GP, Gaasch WH (2004) Clinical practice. Diastolic heart failure. N Engl J Med. 351:1097-1105.

145. Pierce GN and Dhalla NS (1981) Cardiac myofibrillar ATPase activity in diabetic rats. J Mol Cell Cardiol. 13: 1063-1069.

146. Pierce GN and Dhalla NS (1985) Mechanisms of the defect in cardiac myofibrillar function during diabetes. Am J Physiol. 248: E170-E175.

147. Jweied, EE, McKinney RD, Walker LA, Brodsky I, Geha AS, Massad MG, Buttrick PM, de Tombe PP (2005) Depressed cardiac myofilament function in human diabetes mellitus. Am J Physiol Heart Circ Physiol. 289: H2478-H2483.

148. Kodama S, Tanaka S, Heianza Y, Fujihara K, Horikawa C, Shimano H, Saito K, Yamada N, Ohashi Y, Sone H (2013) Association between physical activity and risk of all-cause mortality and cardiovascular disease in patients with diabetes: a meta-analysis. Diabetes Care. 36:471-479.

149. Stolen TO, Hoydal MA, Kemi OJ, Catalucci D, Ceci M, Aasum E, Larsen T, Rolim N, Condorelli G, Smith GL, Wisløff U (2009) Interval training normalizes cardiomyocyte function, diastolic $\mathrm{Ca}^{2+}$ control, and $\mathrm{SR} \mathrm{Ca}^{2+}$ release synchronicity in a mouse model of diabetic cardiomyopathy. Circ Res. 105:527-536.

150. Epp RA, Susser SE, Morissette MP, Kehler DS, Jassal DS, Duhamel TA (2013) Exercise 
training prevents the development of cardiac dysfunction in the low-dose streptozotocin diabetic rats fed a high-fat diet. Can J Physiol Pharmacol. 91: 80-89.

151. DeMarco VG, Aroor AR, Sowers JR (2014) The pathophysiology of hypertension in patients with obesity. Nat Rev Endocrinol. 10:364-376.

152. Voulgari C, Papadogiannis D, Tentolouris N (2010) Diabetic cardiomyopathy: from the pathophysiology of the cardiac myocytes to current diagnosis and management strategies. Vasc Health Risk Manag. 6:883-903.

153. Adler, Al, Neil HA, Manley SE, Holman RR, Turner RC (1999) Hyperglycemia and hyperinsulinemia at diagnosis of diabetes and their association with subsequent cardiovascular disease in the United Kingdom prospective diabetes study (UKPDS 47). Am. Heart J. 138: S353-S359.

154. Chung J, Abraszewski P, Yu X, et al. (2006) Paradoxical increase in ventricular torsion and systolic torsion rate in type I diabetic patients under tight glycemic control. J Am Coll Cardiol. 47:384-390.

155. Sharma AK, Srinivasan BP (2009) Triple verses glimepiride plus metformin therapy on cardiovascular risk biomarkers and diabetic cardiomyopathy in insulin resistance type 2 diabetes mellitus rats. Eur J Pharm Sci. 38:433-444.

156. UK Prospective Diabetes Study (UKPDS) Group (1998) Intensive blood-glucose control with sulphonylureas or insulin compared with conventional treatment and risk of complications in patients with type 2 diabetes (UKPDS 33). Lancet. 352: 837-853.

157. Wong AK, Symon R, AlZadjali MA, Ang DS, Ogston S, Choy A, Petrie JR, Struthers AD, Lang CC (2012) The effect of metformin on insulin resistance and exercise parameters in patients with heart failure. Eur J Heart Fail. 14:1303- 1310.

158. von Bibra H, St John Sutton M (2011) Impact of diabetes on postinfarction heart failure and left ventricular remodeling. Curr Heart Fail Rep. 8:242-251.

159. Mamas MA, Deaton C, Rutter MK, Yuille M, Willams SG, Ray SG, Gibson JM, Neyses L (2010) Impaired glucose tolerance and insulin resistance in heart failure: under recognized and undertreated? J Card Fail. 16:761-768.

160. Young, LH (2003) Insulin resistance and the effects of thiazolidinediones on cardiac metabolism. Am. J. Med. 115: 75S-80S.

161. Inzucchi SE, Zinman B, Wanner C, Ferrari R, Fitchett D, Hantel S, Espadero RM, Woerle HL, Broedi UC, Johnasen OE (2015) SGLT-2 inhibitors and cardiovascular risk: 
proposed pathways and review of ongoing outcome trials. Diab Vasc Dis Res. 12: 90100.

162. Doehner W, Frenneaux M, Anker SD (2014) Metabolic impairment in heart failure: the myocardial and systemic perspective. J Am Coll Cardiol. 64:1388-1400.

163. Bostick B, Habibi J, Ma L, Aroor A, Rehmer N, Hayden MR, Sowers JR (2014) Dipeptidyl peptidase inhibition prevents diastolic dysfunction and reduces myocardial fibrosis in a mouse model of Western diet induced obesity. Metabolism. 63:1000-1011.

164. Chen YH, Feng B, Chen ZW (2012) Statins for primary prevention of cardiovascular and cerebrovascular events in diabetic patients without established cardiovascular diseases: a meta-analysis. Exp Clin Endocrinol Diabetes. 120:116-120.

165. Cholesterol Treatment Trialists' (CTT) Collaborators, Kearney PM, Blackwell L, Collins R, Keech A, Simes J, Peto R, Armitage J, Baigent C (2008) Efficacy of cholesterollowering therapy in 18,686 people with diabetes in 14 randomised trials of statins: a meta-analysis. Lancet. 371:117-125.

166. Van Linthout S, Riad A, Dhayat N, Spillman F, Du J, Westermann D, Hilfiker-Kleiner D, Noutsias M, Laufs U, Schultheiss HO, Tschope C (2007) Anti-inflammatory effects of atorvastatin improve left ventricular function in experimental diabetic cardiomyopathy. Diabetologia. 50:1977-1986.

167. Dai QM, Lu J, Liu NF (2011) Fluvastatin attenuates myocardial interstitial fibrosis and cardiac dysfunction in diabetic rats by inhibiting over-expression of connective tissue growth factor. Chin Med J (Engl). 124:89-94.

168. Lowes BD, Gill EA, Abraham W T, Larrain JR, Robertson AD, Bristow MR, Gilbert EM (1999) Effects of carvedilol on left ventricular function mass, chamber geometry, and mitral regurgitation in chronic heart failure. Am. J. Cardiol. 83: 1201-1205.

169. Waagstein F, Bristow M, Swedburg K (1993) Beneficial effects of metoprolol in idiopathic dilated cardiomyopathy. Lancet. 342: 1441-1446.

170. The Cardiac Insufficiency Bisoprolol Study (CIBIS) Investigators and Committees (1994) A Randomised trial of $\beta$-blockade in heart failure: The Cardiac Insufficiency Bisoprolol Study (CIBIS). Circ. 90: 1765-1773.

171. CIBIS II Investigators and Committees (1999) The Cardiac Insufficiency Bisoprolol Study (CIBIS II): a randomised trial. Lancet 353: 9-13.

172. Merit-HF Study Group (1999) Effect of Metoprolol CR/XL in chronic Heart failure: Metoprolol CR/XL Randomised Intervention Trial in Congestive Heart Failure (MERIT- 
HF). Lancet. 353: 2001-2007.

173. Packer M, Bristow M, Cohn J (1996) The effect of carvedilol on morbidity and mortality in patients with chronic heart failure. N. Engl. J. Med. 334: 1349-1355.

174. Bristow MR (2001) beta-adrenergic receptor blockade in chronic heart failure. Circ. 101:558-569.

175. Sharma V, McNeill JH (2011) Parallel effects of $\beta$-adrenoceptor blockade on cardiac function and fatty acid oxidation in the diabetic heart: confronting the maze. World J Cardiol. 3:281-302.

176. Mancia G, Fagard R, Narkiewicz K, et al., (2013) 2013 ESH/ESC guidelines for the management of arterial hypertension: the Task Force for the management of arterial hypertension of the European Society of Hypertension (ESH) and of the European Society of Cardiology (ESC). European Heart Journal. 28: 2159-2219.

177. Thomas CM, Yong QC, Seqqat R, Chandel N, Feldman DL, Baker KM, Kumar R (2013) Direct renin inhibition prevents cardiac dysfunction in a diabetic mouse model: comparison with an angiotensin receptor antagonist and angiotensin-converting enzyme inhibitor. Clin Sci (Lond). 124:529-541.

178. Machackova J, Liu X, Lukas A, Dhalla NS (2004) Renin-angiotensin blockade attenuates cardiac myofibrillar remodelling in chronic diabetes. Mol Cell Biochem. 261:271-278.

179. Symeonides P, Koulouris S, Vratsista E, Triantafyllou K, Ioannidis G, Thalassinos N, Katritsis D (2007) Both ramipril and telmisartan reverse indices of early diabetic cardiomyopathy: a comparative study. Eur J Echocardiogr. 8:480-486.

180. Szabo, C (2002) PARP as a drug target for the therapy of diabetic cardiovascular dysfunction. Drug News Perspect. 15: 197-205.

181. Du X, Matsumura T, Edelstein D, Rossetti L, Zsengeller Z, Szabo C, Brownlee M (2003) Inhibition of GAPDH activity by poly (ADP-ribose) polymerase activates three major pathways of hyperglycemic damage in endothelial cells. J. Clin. Invest. 112, 10491057.

182. Zhao P, Zhang J, Yin XG, Maharaj P, Narraindoo S, Cui LQ, Tang YS (2013) The effect of trimetazidine on cardiac function in diabetic patients with idiopathic dilated cardiomyopathy. Life Sci. 92:633-638.

183. Li YJ, Wang PH, Chen C, Zou MH, Wang DW (2010) Improvement of mechanical heart function by trimetazidine in db/db mice. Acta Pharmacol Sin. 31:560-569. 
184. Sulaiman M, Matta MJ, Sunderesan NR, Gupta MP, Periasamy M, Gupta M (2010) Resveratrol, an activator of SIRT1, upregulates sarcoplasmic calcium ATPase and improves cardiac function in diabetic cardiomyopathy. Am J Physiol Heart Circ Physiol. 298:H833-H843.

185. Maier LS, Layug B, Karwatowska-Prokopczuk E, Belardinelli L, Sander J, Lang C, Wachter R, Edelmann F, Hasenfuss G, Jacobshagen C (2013) RAnoLazlne for the treatment of diastolic heart failure in patients with preserved ejection fraction: the RALI-DHF proof-of-concept study. JACC Heart Fail. 1:115-122.

186. Huynh K, Bernardo BC, McMullen JR, Ritchie RH (2014) Diabetic cardiomyopathy: mechanisms and new treatment strategies targeting antioxidant signaling pathways. Pharmacol Ther. 142:375-415.

187. Leon LE, Rani S, Fernandez M, Larico M, S. D. Calligaris SD (2016) Subclinical detection of diabetic cardiomyopathy withMicroRNAs: challenges and perspectives. J Diabetes Res. DOI: 10.1155/2016/6143129.

188. Yildirim SS, Akman D, Catalucci D, Turan B (2013) Relationship between downregulation of miRNAs and increase of oxidative stress in the development of diabetic cardiac dysfunction: junctin as a target protein of miR-1. Cell Biochemistry and Biophysics. 67: 1397-1408.

189. Thum T, Gross C, Fiedler J, Fischer T, Kissler S, Bussen M, Galuppo P, Just S, Rottbauer W, Frantz S, Castoldi M, Soutschek J, Koteliansky V, Rosenwald A, Basson MA, Licht JD, Pena JT, Rouhanifard SH, Muckenthaler MU, Tuschl T, Martin GR, Bauersachs J, Engelhardt S (2008) MicroRNA-21 contributes to myocardial disease by stimulating MAP kinase signalling in fibroblasts. Nature. 18: 456(7224): 980-4. DOI: 10.1038/nature07511.

190. Tan Y, Ichikawa T, Li J, Si Q, Yang H, Chen X, Goldblatt CS, Meyer CJ, Li X, Cai L, Cui T (2011) Diabetic downregulation of Nrf2 activity via ERK contributes to oxidative stress-induced insulin resistance in cardiac cells in vitro and in vivo. Diabetes. 60(2): 625-33. DOI: $10.2337 / \mathrm{db} 10-1164$.

191. Mortensen SA, Rosenfeldt F, Kumar A, et al. (2014) The effect of coenzyme Q10 on morbidity and mortality in chronic heart failure: results from Q-SYMBIO: a randomized double-blind trial. JACC Heart Fail. 2:641-649.

192. Xu YJ, Tappia PS, Neki NS, Dhalla NS (2014) Prevention of diabetes-induced cardiovascular complications upon treatment with antioxidants. Heart Fail Rev. 
19:113-121.

193. Huynh K, Kiriazis H, Du XJ, Love JE, Jandeleit-Dahm KA, Forbes JM, McMullen JR, Ritchie RH (2012) Coenzyme Q10 attenuates diastolic dysfunction, cardiomyocyte hypertrophy and cardiac fibrosis in the $\mathrm{db} / \mathrm{db}$ mouse model of type 2 diabetes. Diabetologia. 55:1544-1553.

194. Katare R, Caporali A, Zentilin L, Avolio E, Sala-Newby G, Oikawa A, Cesslli D, Beltram AP, Giacca M, Emanuel C, Madeddu P (2011) Intravenous gene therapy with PIM-1 via a cardiotropic viral vector halts the progression of diabetic cardiomyopathy through promotion of prosurvival signaling. Circ Res. 108:1238- 1251.

195. Meloni M, Descamps B, Caporali A, Zentilin L, Floris I, Giacca M, Emanueli C (2012) Nerve growth factor gene therapy using adeno-associated viral vectors prevents cardiomyopathy in type 1 diabetic mice. Diabetes. 61:229-240.

196. Prakoso D, De Blasio MJ, Qin C, Rosli S Kiriazis H, Qian H, Du XJ, Weeks KL, Gregorevic P, McMullen JR, Ritchie RH (2017) Phosphoinositide 3-kinase ( $1110 \alpha)$ gene delivery limits diabetes-induced cardiac NADPH oxidase and cardiomyopathy in a mouse model with established diastolic dysfunction. Clin Sci (Lond). 131(12): 1345-1360. DOI: 10.1042/CS20170063.

197. Szeto HH (2006) Cell-permeable, mitochondrial-targeted, peptide antioxidants. AAPS J. 8: E277-E283. 